\title{
Identification of periplakin as a major regulator of lung injury and repair in mice
}

\author{
Valérie Besnard, ${ }^{1}$ Rania Dagher, ${ }^{1}$ Tania Madjer, ${ }^{1}$ Audrey Joannes, ${ }^{1}$ Madeleine Jaillet, ${ }^{1}$ Martin Kolb, ${ }^{2}$ \\ Philippe Bonniaud, ${ }^{3}$ Lynne A. Murray, ${ }^{4,5}$ Matthew A. Sleeman, ${ }^{4}$ and Bruno Crestani ${ }^{1}{ }^{16,7}$ \\ 'INSERM U1152, Paris, France. ²Department of Medecine, Firestone Institute for respiratory Health, McMaster University \\ and The Research Institute of St. Joe's Hamilton, Hamilton, Canada. ${ }^{3}$ INSERM U866, Université de Bourgogne, Dijon, \\ France. ${ }^{4}$ Medlmmune Ltd, Granta Park, Cambridgeshire, United Kingdom. ${ }^{5}$ Respiratory, Inflammation, Autoimmunity \\ (RIA) IMED Biotech unit, AstraZeneca, Gothenburg, Sweden. 'Université Paris Diderot, LABEX INFLAMEX, Paris, France. \\ ${ }^{7}$ Assistance Publique-Hôpitaux de Paris, DHU FIRE, Hôpital Bichat, Paris, France.
}

Periplakin is a component of the desmosomes that acts as a cytolinker between intermediate filament scaffolding and the desmosomal plaque. Periplakin is strongly expressed by epithelial cells in the lung and is a target antigen for autoimmunity in idiopathic pulmonary fibrosis. The aim of this study was to determine the role of periplakin during lung injury and remodeling in a mouse model of lung fibrosis induced by bleomycin. We found that periplakin expression was downregulated in the whole lung and in alveolar epithelial cells following bleomycin-induced injury. Deletion of the $P p /$ gene in mice improved survival and reduced lung fibrosis development after bleomycin-induced injury. Notably, Ppl deletion promoted an antiinflammatory alveolar environment linked to profound changes in type 2 alveolar epithelial cells, including overexpression of antiinflammatory cytokines, decreased expression of profibrotic mediators, and altered cell signaling with a reduced response to TCF- $\beta 1$. These results identify periplakin as a previously unidentified regulator of the response to injury in the lung.

Conflict of interest: The authors have declared that no conflict of interest exists.

Submitted: September 2, 2016

Accepted: January 25, 2018

Published: March 8, 2018

Reference information: JCI Insight. 2018;3(5):e90163. https:// doi.org/10.1172/jii.insight.90163.

\section{Introduction}

Idiopathic pulmonary fibrosis (IPF) is a progressive fibrotic disease leading to severe alterations in lung function and gas exchange. The disease is characterized by interstitial expansion of the extracellular matrix, with prominent fibroblastic foci and mild interstitial inflammation. The disease progresses relentlessly, leading to death from progressive respiratory failure. The current hypothesis is that IPF is a type of aberrant and uncontrolled wound healing - arising from repeated microinsults of unknown etiology, to alveolar epithelial cells (AECs) - leading to the recruitment, activation, and proliferation of mesenchymal cells.

In mammalian tissues, epithelial cell polarity and intercellular adhesion is mediated through the assembly of tight junctions, adherence junctions, and desmosomes. Desmosomes provide strong adhesion between cells and are particularly abundant in tissues that are continually subjected to mechanical forces, including heart, lung, and epidermis. Desmosomes are composed of desmosomal cadherins, proteins from the armadillo family, and members of the plakin family (desmoplakin, plectin, periplakin [PPL], envoplakin) (1). PPL acts as a cytolinker between intermediate filament scaffolding and the desmosomal plaque. In addition, PPL is capable of interacting with other nondesmosomal proteins at the plasma membrane such as AKT (2), Annexin 9 (3), Fc $\gamma \mathrm{RI}(\mathrm{CD} 64)(4,5)$, and melanin concentrating hormone receptor 1 (MCHR1) (6) and modulates their signaling pathway. In the lung, PPL is expressed in both lung proximal and distal airway epithelia (7).

Recent studies support the concept that alterations of cell junctions may be responsible for loss of lung epithelium integrity, resulting in fibrogenesis. Analysis of expression profiles in a murine model of lung fibrosis induced by bleomycin showed enrichment in genes associated with cell junction organization and cell-substrate junction assembly during both the inflammatory and the fibrotic phases (8). In a genomewide association study, Fingerlin et al. identified polymorphisms in the desmoplakin gene, another plakin family member, as a potential genetic risk factor in $\operatorname{IPF}(9,10)$. Mechanisms by which cell junctions ensure epithelium integrity during fibrogenesis remain poorly understood.

In a previous study, our group identified the presence of autoantibodies against PPL in the serum and the bronchoalveolar lavage fluid (BALF) from approximately $40 \%$ of IPF patients (7). The presence of 
anti-PPL IgG was associated with increased severity of IPF. In addition, PPL localization was altered in lung AECs from IPF patients. In paraneoplastic pemphigus, an autoimmune disease producing autoantibodies against PPL and envoplakin (11), both bronchial epithelium and alveoli may be affected by the disease (12). These results suggest that PPL may be a target in lung disease, possibly by altering lung alveolar cell adhesion and the integrity of the alveolar epithelium.

In the present study, we aimed to determine the role of PPL during lung injury and remodeling in a murine model of lung fibrosis induced by bleomycin. We found that PPL expression was downregulated in the whole lung and in AECs after bleomycin-induced injury. Deletion of $P p l$ reduced lung fibrosis after bleomycin injury by promoting antiinflammatory cytokine expression and profoundly altering cellular signaling in AECs, including STAT3 activation, and TGF- $\beta$ /smad pathway activation. These results identify PPL as a previously unidentified regulator of the response to injury in the alveolar epithelium.

\section{Results}

PPL was downregulated after bleomycin injury. We have previously shown PPL expression in the epithelium of IPF patients (7). Here, we investigated the expression of PPL in the mouse lung by quantitative PCR (qPCR) and Western blot in WT mice in basal condition and 3, 7, and 14 days after intratracheal instillation of bleomycin (Figure 1, A and B). At day 3 (D3), there was a significant decrease of $P p l$ mRNA levels that was sustained at D7 and D14 compared with D0. These results were also observed in PPL protein levels by Western blot (Figure 1B). PPL location was assessed by IHC in mouse lungs in basal and 14 days after intratracheal instillation of bleomycin (Figure 1, C-E). In uninjured lung, PPL was detected in the alveolar epithelium (Figure 1C). By contrast, on D14, PPL was absent in areas with lung architecture disruption and remained present in areas with less severe lung injuries (Figure 1D).

To determine the mechanisms involved in the inhibition of PPL expression in a profibrotic environment, we cultured murine type 2 epithelial cells (MLE-15 cells) in the presence of BALF from control or IPF patients. $P p l$ mRNA levels were reduced by $50 \%$ in the presence of IPF BALF, while control BAL had no effect (Figure $1 \mathrm{~F}$ ). These data demonstrate that soluble factors present in the alveolar environment in the fibrotic lung can regulate PPL expression. We next assessed whether TGF- $\beta 1$ and PDGF-BB, 2 major mediators of the fibrotic process, act as PPL regulators. Indeed, TGF- $\beta 1$ and PDGF-BB downregulated $P p l$ mRNA levels in MLE-15 epithelial cells (Figure 1, G and H). Similar results were observed with the treatment of primary murine type 2 AECs (AEC2) by TGF- $\beta 1$ (Supplemental Figure 2; supplemental material available online with this article; https://doi.org/10.1172/jci.insight.90163DS1). In addition, effects of proinflammatory cytokines TNF $\alpha$ and IL-1 $\beta$ on $P p l$ mRNAs were assessed in AEC2. $P p l$ mRNA levels decreased in response to TNF $\alpha$ and IL-1 $\beta$ in AECs (Supplemental Figure 2, D and E). These results indicate that lung injury is associated with a sustained decrease of PPL expression that is likely coordinated through different mediators present in the alveolar milieu during the fibrotic process.

To better understand the mechanisms leading to the reduced expression of PPL in AECs, we analyzed the promoter region of the mouse $P p l$ gene in silico. We identified binding regions for Krüppel-like factor 5 (Klf5) and early growth response gene 2 (Egr2). We therefore examined the expression of Klf5 and Egr2 mRNA in vitro and in vivo. In vitro in primary lung epithelial cells (Figure 2A) and in MLE-15 cells (Supplemental Figure 3A), Klf5 mRNA levels were markedly reduced in the presence of IPF BALF, while control BAL had no effect. By contrast, Egr2 was significantly induced in response to IPF BALF (Figure 2B and Supplemental Figure 3B). Likewise, we assessed Klf5 and Egr2 expression in both lung primary epithelial cells and MLE- 15 cells in response to TGF- $\beta 1$. Similarly to IPF BALF, TGF- $\beta 1$ decreased Klf5 mRNA expression and increased Egr2 mRNA expression (Figure 2, A and B and Supplemental Figure 3, A and B). In vivo, Klf5 mRNA is decreased as early as 3 days after bleomycin challenge, and that inhibition was maintained until D14 (Figure 2C). In contrast, Egr2 mRNA expression was markedly increased 7 days after bleomycin injury and further increased at D14 (Figure 2D). To demonstrate the role of these transcription factors in the regulation of $P p l$, KLF5 and EGR2 were overexpressed in MLE-15 cells. KLF5 increased $P p l$ mRNA (Figure 2E), while EGR2 decreased $P p l$ expression (Figure 2F).

$\mathrm{Ppl}^{-1-}$ mice were protected from bleomycin injury. To determine whether inhibition of PPL expression observed in the bleomycin-induced fibrosis played a role in the pathophysiology of the fibrotic process, we used $\mathrm{Ppt}^{-1-}$ mice. These mice develop normally and are healthy and fertile at baseline, with normal lung morphology, suggesting that PPL does not play a critical role in pulmonary homeostasis in the postnatal lung under normal conditions (13). 
A

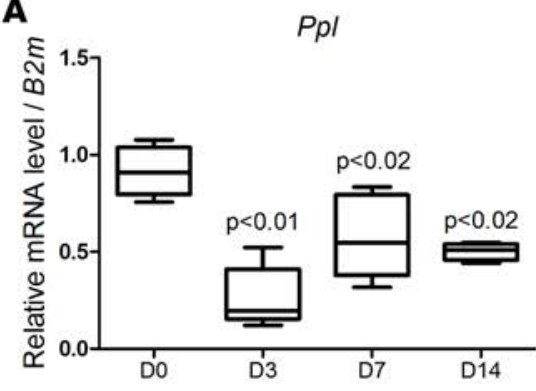

B

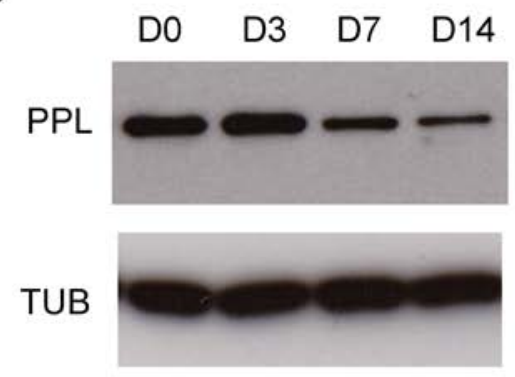

PPL

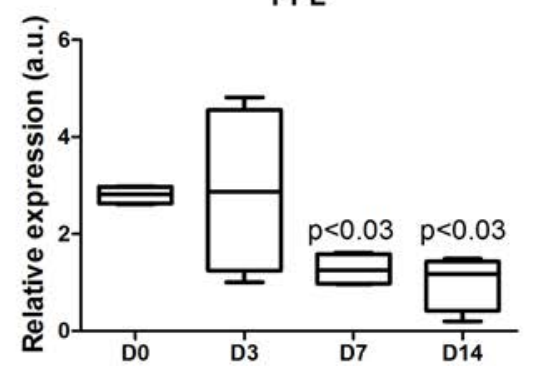

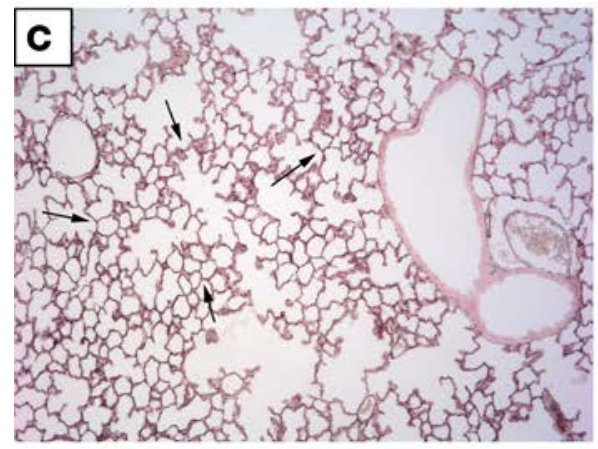

$\mathbf{F}$

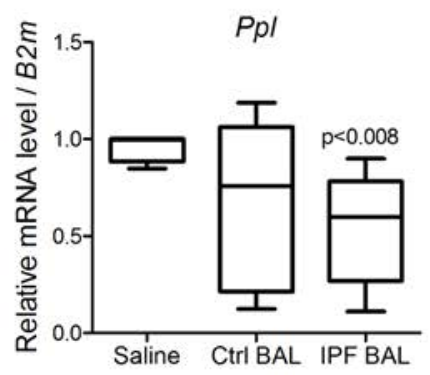

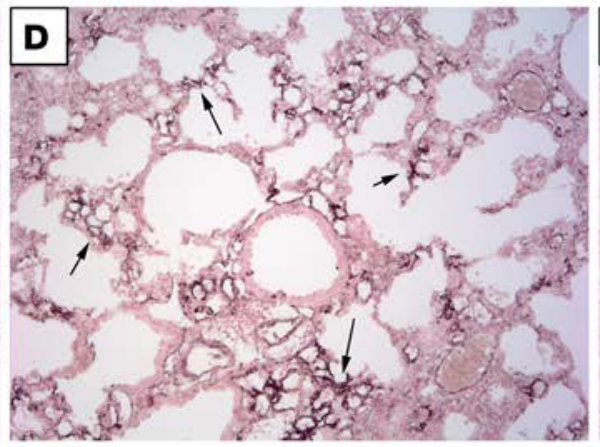

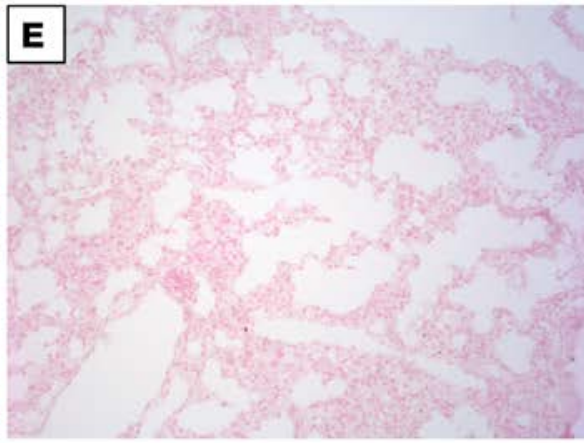

G

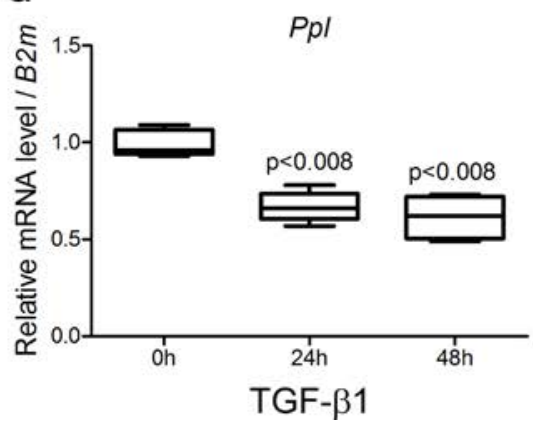

H

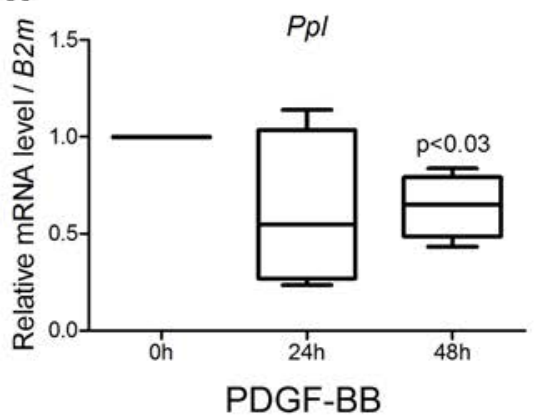

Figure 1. Expression of PPL is decreased after lung injury. (A) qPCR was performed to estimate $P p /$ mRNA in whole-lung homogenate from $P p l^{+/+}$mice at indicated time points after bleomycin instillation and normalized to $B 2 \mathrm{~m}$ mRNA. Results are expressed as means \pm SEM of 5 animals per group. (B) Immunoblotting for PPL was performed on $\mathrm{Ppl}^{+/+}$lungs on D0, D3, D7, and D14 after bleomycin instillation. Western blot analysis demonstrated a marked decrease in PPL protein in Pp/+/+ lungs compared with DO. IHC for PPL (black staining) was performed on mouse lungs on D0 (C) and D14 (D) after bleomycin instillation. Arrows indicate PPL staining in lung AECs. Goat isotype is shown in E. (F) MLE-15 cells were exposed to either saline (0.9\% NaCl), or BALF from control (Ctrl) or (IPF) human patient for 24 hours. Ppl mRNAs were assessed by qPCR and normalized to the $\beta 2$-microglobulin (B2m) gene. $n$ = 5. (G) MLE-15 cells were exposed to either hTGF- $\beta 1$ (G) or hPDGF-BB (H) for 24 and 48 hours. Ppl mRNAs were assessed by qPCR and normalized to the $\beta 2$-microglobulin $(B 2 m)$ gene. $n=5 .{ }^{*} P<0.05 ;{ }^{* *} P<0.01$, Mann Whitney U test. Magnification $\times 40$.

In order to assess the role of PPL during lung injury and repair, we treated $\mathrm{Ppl}^{+{ }^{++}}$and $\mathrm{Ppt}^{\mathrm{I}^{-}}$mice with intratracheal instillation of bleomycin. The overall health and survival was monitored, and individual weights within each group were measured. In the control groups (saline-treated mice), survival rate and body weight were similar in $\mathrm{Ppl}^{+^{++}}$and $\mathrm{Ppl}^{\mathrm{I}^{--}}$mice. Most importantly, bleomycin-treated $\mathrm{Ppl}^{-1-}$ mice had an improved survival compared with $\mathrm{Ppl}^{+/+}$mice (Figure 3A). This result was supported by rapid weight loss that began on D4 after bleomycin treatment for $\mathrm{Ppl}^{+/+}$, whereas weight loss in $\mathrm{Ppl}^{-/-}$mice was delayed and less severe (Supplemental Figure 4A). No histological differences were observed between $\mathrm{Ppl}^{+/+}$and $\mathrm{Ppl}^{-1-}$ mice at baseline (D0, Figure 3, B, C, G, and H). In contrast, on D14, while lungs from bleomycin-treated $\mathrm{Ppl}^{+/+}$mice had extensive disruption of lung architecture, $\mathrm{Ppl}^{\mathrm{H}^{--}}$mouse lungs showed less severe lung injury (Figure 3, D and E, and Supplemental Figure 4K). Type 1 and type 3 collagen depositions were less extensive in $\mathrm{Ppl}^{-/-}$mice compared with $\mathrm{Ppl}^{+/+}$mice (Figure 3, I and J, and Supplemental Figure 4, B-E). These results were confirmed by biochemical quantification (Sircol assay) in lung homogenates of each experimental group (Figure 3F). Similarly, collagen and fibronectin content were reduced in $\mathrm{Ppt}^{-1}$ mice compared 
A

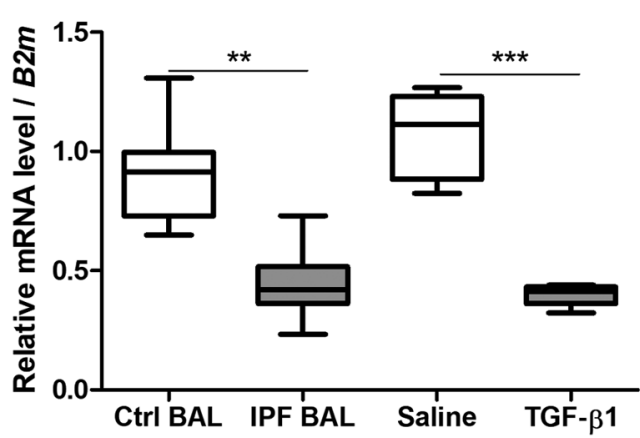

B

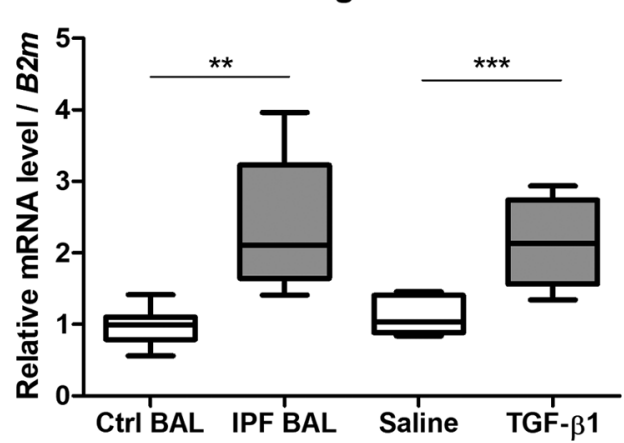

C

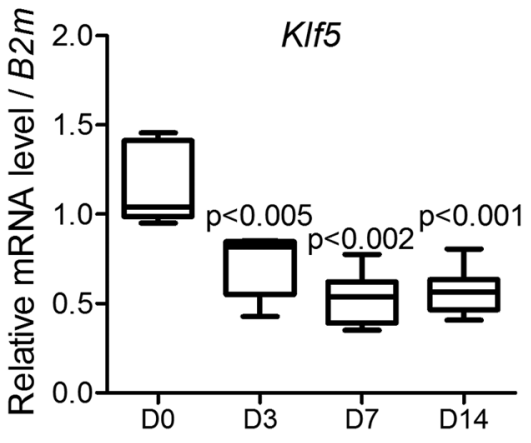

D

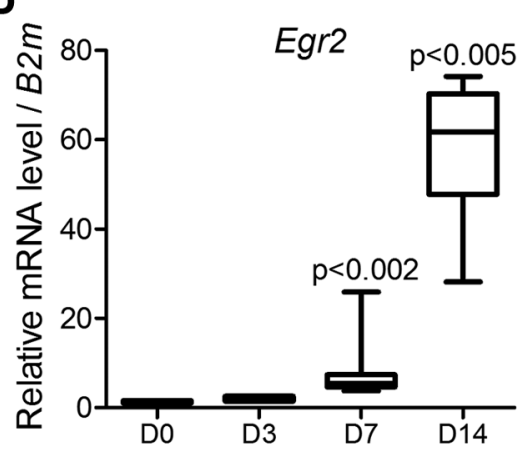

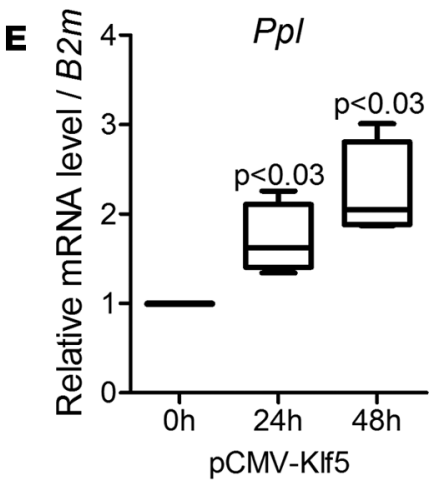

$\mathbf{F}$

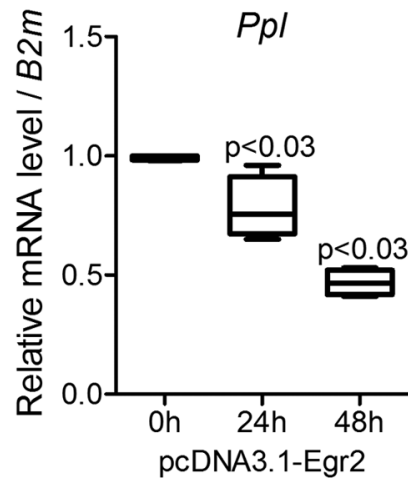

Figure 2. KIf5 and Egr2 regulate Ppl gene transcription. MLE-15 cells were exposed to either BALF from control (Ctrl) or (IPF) human patients, or saline $(0.9 \% \mathrm{NaCl}$ ) or hTGF- $\beta 1$ for 24 hours and $K I f 5$ (A) and Egr2 (B). mRNAs were assessed by qPCR and normalized to the $\beta 2$-microglobulin (B2m) gene. qPCR was performed to estimate $K I f 5$ (C) and Egr2 (D) mRNA in whole-lung homogenate from Pp/+/+ mice at indicated time points after bleomycin instillation and normalized to $B 2 \mathrm{~m}$ mRNA. Results are expressed as means \pm SEM of 5 animals per group. Ppl mRNA levels were assessed by qPCR and normalized to the B2m gene in MLE-15 cells transfected by plasmids expressing either pCMV-KIf5 (E) or pcDNA3.1-Egr2 (F) for 24 and 48 hours. $n=5$. ${ }^{* *} P<0.01 ;{ }^{* *} P<0.001$, Mann Whitney $U$ test.

with $\mathrm{Ppl}^{+/+}$mice, as assessed by Western blot (Figure 3K). Histological findings were consistent with $\mathrm{Fn1}$ and Col3a1 mRNA levels, both being significantly less induced by bleomycin in $\mathrm{Ppt}^{-1-}$ mice compared with $\mathrm{Ppl}^{+/+}$mice (Supplemental Figure 4, F-J). Altogether, these data demonstrate that PPL deletion protected mice from bleomycin-induced pulmonary fibrosis.

To determine whether PPL deletion could protect mice from lung fibrosis in a noninflammatory context, $\mathrm{Ppl}^{+/+}$and $\mathrm{Ppl}^{-/-}$mice received an intratracheal instillation of control or TGF- $\beta 1$-expressing adenovirus (Ad-Ctrl and Ad-TGF- $\beta 1$, respectively). In both Ad-Ctrl and Ad-TGF- $\beta 1$ groups, survival rate and body weight were similar in $\mathrm{Ppl}^{+/+}$and $\mathrm{Ppl}^{-/-}$mice. No histological differences were observed between $\mathrm{Ppl}^{+/+}$ and $\mathrm{Ppl}^{\mathrm{H}^{-}}$mice receiving Ad-Ctrl (Figure 4, A and B). By contrast, on D28, while lungs from Ad-TGF- $\beta 1-$ treated $\mathrm{Ppl}^{+/+}$mice showed fibroblastic foci in interstitial areas (Figure 4C), lung fibrosis was markedly reduced in $\mathrm{Ppl}^{-1-}$ mice (Figure 4D). These results were confirmed by Sircol assay in lung homogenates of each experimental group (Figure 4E). In addition, mRNA levels of Col1a1, Col3a1, and Fn1 were significantly reduced in $\mathrm{Ppt}^{-1-}$ lungs treated by Ad-TGF- $\beta 1$ (Figure 4F). Altogether, these data demonstrate that PPL deletion also protected mice from Ad-TGF- $\beta 1$-induced pulmonary fibrosis.

TGF- $\beta$ /Smad signaling was altered in $\mathrm{Ppt}^{-1-}$ mice. TGF- $\beta 1$ is a profibrotic factor overexpressed after bleomycin-induced injury. While $T g f b 1$ mRNA levels were increased in response to bleomycin treatment in each mouse group, $\mathrm{Tg} f b 1 \mathrm{mRNA}$ level was significantly less in $\mathrm{Ppt}^{\mathrm{I}^{-}}$mice compared with $\mathrm{Ppl}^{\mathrm{I}^{++}}$mice 14 days after intratracheal bleomycin (Figure 5A). Free TGF- $\beta 1$ protein levels were markedly reduced in both BAL and lung homogenate from $\mathrm{Ppl}^{-/}$mice compared with $\mathrm{Ppl}^{+/+}$mice after bleomycin treatment (Figure 5, B and C).

Activation of the TGF- $\beta$ /Smad signaling pathway is a major profibrotic event in lung fibrosis, particularly after bleomycin injury (14). To determine whether the TGF- $\beta$ /Smad pathway was altered in the absence of PPL, we assessed Smad2 activation and Smad4 expression in the lung by Western blot. 

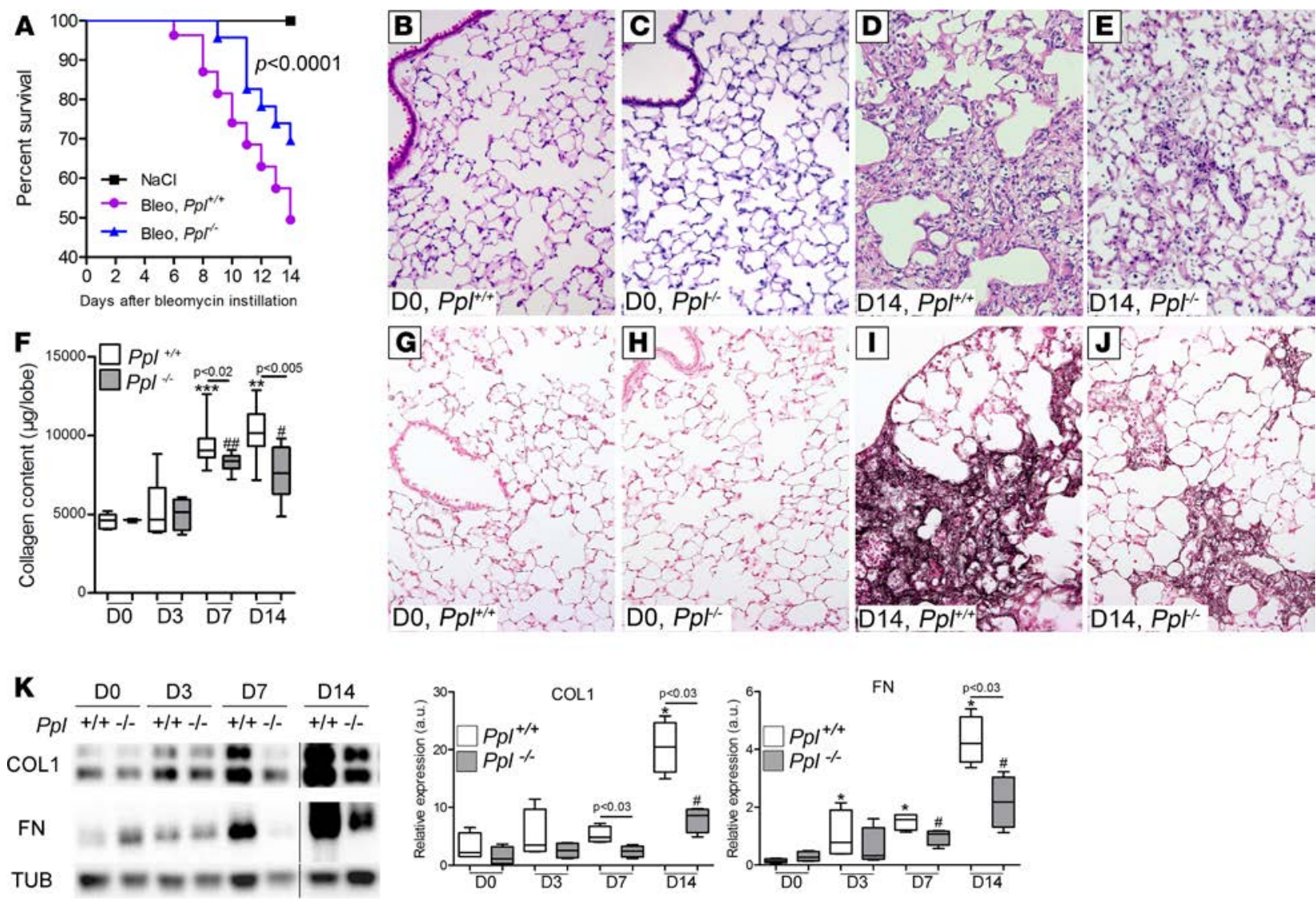

Figure 3. $\mathrm{Pp}^{-/-}$mice were protected from bleomycin injury. (A) Kaplan-Meier plot of survival of $\mathrm{Ppl}^{\mathrm{I}^{++}}$and $P \mathrm{Pl}^{-/-}$mice after bleomycin exposure. Eightweek-old $\mathrm{Ppl}^{l_{++}}$and $\mathrm{Ppl}^{-/-}$mice received an intratracheal instillation of bleomycin or saline (NaCl) at day0. Survival of $P \mathrm{pl}^{-/-}$mice $(n=23)$ after bleomycin was significantly increased compared with controls $(n=40) . P<0.0001$ by Log-rank test. (B-E) Lung histology of $P p 1^{l^{++}}$and $P p 1^{-/-}$mice after bleomycin treatment. Lung sections of $\mathrm{Ppl}^{+/+}$and $\mathrm{Ppl}^{-/-}$mice were prepared at DO, D3, D7, and D14 after bleomycin exposure and stained with $\mathrm{H} \& \mathrm{E}$ to assess lung morphology. (F) Soluble collagen content, assessed by Sircol assay in lung homogenates, was decreased in $P \mathrm{pl}^{-/-}$mice compared with $P \mathrm{pl}^{+/+}$mice $(n=10$ mice per group). (G-J) Collagen deposition was assessed by immunostaining for type I collagen (COL1, black staining) on lung sections of $P p{ }^{l^{++}}$(G and $\left.\mathbf{I}\right)$ and $\mathrm{Ppl}^{-/-}$mice (H and $\left.\mathbf{J}\right)$ prepared at DO and D14 after bleomycin exposure. The figure is representative of at least 6 individual mice at each time. Magnification $\times 20$. (K) Immunoblotting for collagen 1 (COL1) and fibronectin (FN) was performed on $\mathrm{Ppl}^{+^{++}}$and $\mathrm{Pp}^{-/-}$lungs on DO, D3, D7, and D14 after bleomycin instillation. Western blot analysis demonstrated a marked decrease in both COL1 and FN proteins in $P \mathrm{pl}^{-/-}$lungs compared with $P \mathrm{pl}^{+/+}$. ${ }^{*} P<0.05 \mathrm{vs}$. (DO, $\left.P \mathrm{pl}^{+/+}\right)$;

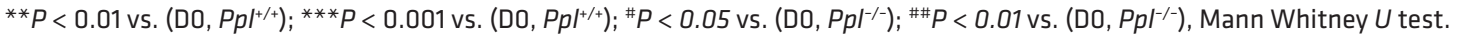

In basal condition, phosphorylated-Smad2/Smad2 (P-Smad2/Smad2) ratio was similar in $\mathrm{Ppt}^{-1-}$ and $\mathrm{Ppl}^{+/+}$mice (Figure 5D). In response to bleomycin, the P-Smad2/Smad2 ratio was increased in lung tissues from both genotypes, with lower levels detected in $\mathrm{Ppt}^{-1-}$ mice, indicating a reduced activation of the canonical TGF- $\beta$ /Smad pathway in the absence of PPL (Figure 5D). Smad4 plays a key role in Smad signaling by enhancing Smad2 promoter activity $(15,16)$. Strikingly, immunoblotting showed that Smad4 protein expression was severely decreased in $\mathrm{Ppl}^{\mathrm{t}^{-}}$lungs compared with $\mathrm{Ppl}^{+/+}$lungs in both control and bleomycin conditions (Figure 5E). A similar decrease in Smad4 mRNA levels was observed in $\mathrm{Ppt}^{-/}$lungs compared with $\mathrm{Ppl}^{+/+}$lungs (Figure 5F). These data indicate that the absence of PPL is associated with an inhibition of bleomycin-induced TGF- $\beta$ and TGF- $\beta$ /Smad signaling, with a profound inhibition of Smad4 expression. To determine whether $P p l$ deficiency alters activation of latent TGF- $\beta 1$, expression of both Itgb6 and Itgav was assayed by qPCR in primary lung epithelial cells from $\mathrm{Ppl}^{-/}$and $\mathrm{Ppl}^{+/+}$in basal conditions and in response to either TGF- $\beta 1$ or after bleomycin exposure. Itgb6 mRNA levels were markedly reduced in $\mathrm{Ppl}^{-1-}$ cells at baseline and were felt to be induced in response to TGF- $\beta 1$ or bleomycin compared with $\mathrm{Ppl}^{+/+}$cells (Figure 5G). By contrast, lung epithelial $\mathrm{Ppt}^{-1-}$ cells expressed similar levels of Itgav mRNAs at baseline or in response to treatments (Figure $5 \mathrm{H}$ ). These results indicate that $P p l$ deficiency alters the TGF- $\beta /$ Smad signaling through a reduction in of latent TGF- $\beta 1$ activation. 


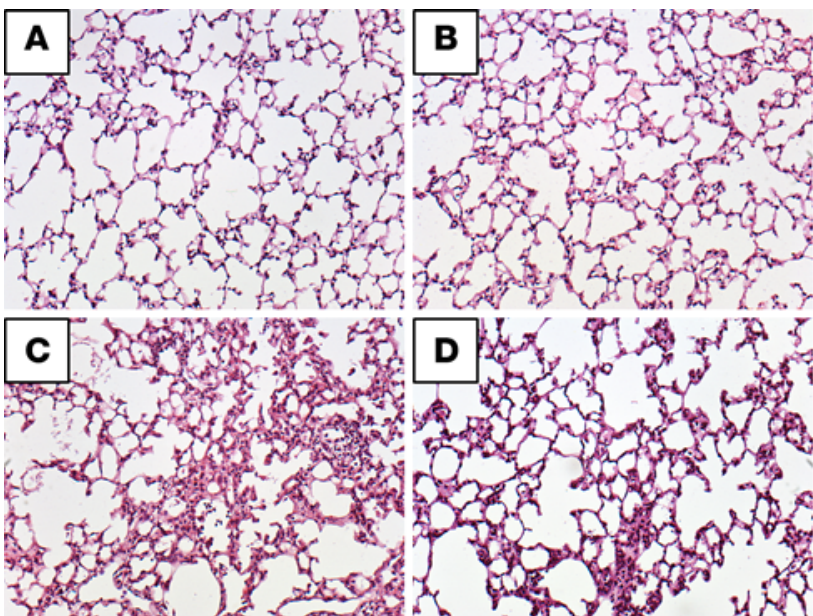

F Col1a1

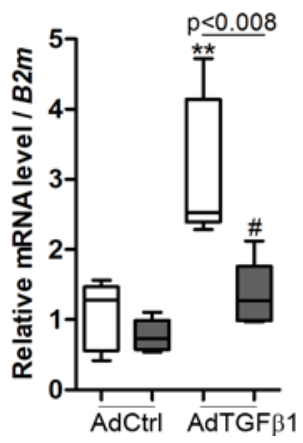

Col3a1

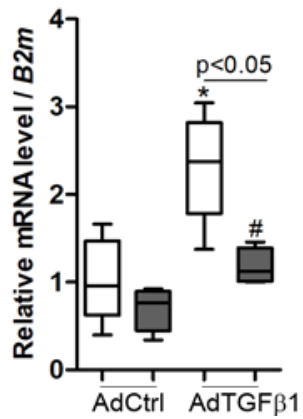

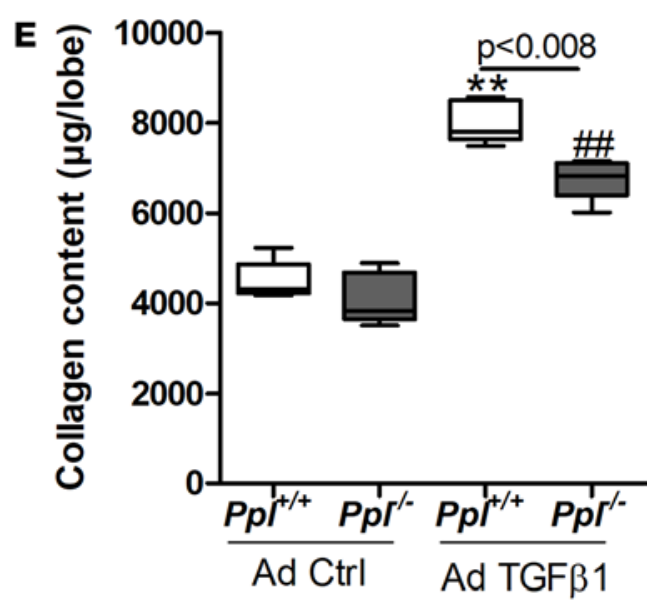

Fn1

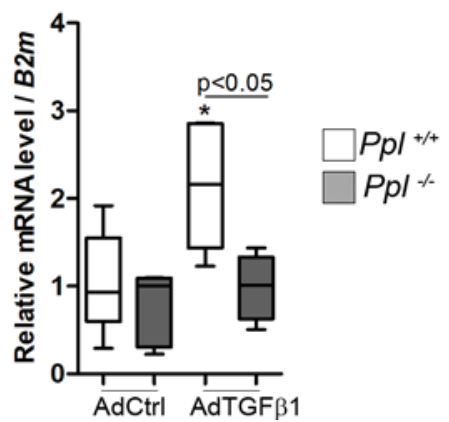

Figure 4. Lung fibrosis is reduced in $\mathbf{P p l}^{-/-}$exposed to Ad-TGF- $\boldsymbol{\beta 1}$. (A-D) Lung histology of $P \mathrm{Pl}^{+/+}$and $\mathrm{Ppl}^{\mathrm{F}^{-/}}$mice after Ad-TCF- $\beta 1$ exposure. Lung sections of $\mathrm{Ppl}^{+/+}(\mathbf{A}$ and $\mathbf{C})$ and $\mathrm{Ppl}^{-/-}(\mathbf{B}$ and $\mathbf{D})$ mice were prepared at D28 after Ad-Ctrl (A and B) or Ad-TGF- $\beta 1$ (C and $\left.\mathbf{D}\right)$ exposure and stained with H\&E to assess lung morphology. Magnification $\times 40$. (E) Soluble collagen content, determined by Sircol assay in lung homogenates, was decreased in $P \mathrm{pl}^{-1-}$ mice compared with $\mathrm{Ppl}^{l^{++}}$mice in response to Ad-TCF- $\beta 1$ ( $n=5$ mice per group). (F) qPCR was performed to evaluate Col1a1, Col3a1, and Fn1 mRNAs in whole-lung homogenate from $\mathrm{Ppl}^{+/+}$and $\mathrm{Pp}^{-/-}$mice after Ad-Ctrl or Ad-TCF- $\beta 1$ instillation and normalized to $B 2 \mathrm{~m}$ mRNA. Results are expressed as means \pm SEM of 5 animals per group. ${ }^{*} P<0.05$ vs. (DO, $P \mathrm{l}^{+/+}$); ${ }^{* *} P<0.01$ vs. (DO, $P \mathrm{Pl}^{+++}$); ${ }^{*} P<0.05$ vs. (DO, $P p \mathrm{l}^{-/}$); ${ }^{\# \#} P<0.01$ vs. (DO, $P \mathrm{P}^{-/-}$), Mann Whitney $U$ test.

$\alpha B$-crystallin expression was altered in $\mathrm{Ppl}^{{ }^{-1}}$ mice. Recent studies have shown that the small heat shock protein $\alpha \mathrm{B}$-crystallin controls the nuclear localization of Smad4 in AECs and lung fibroblasts, is essential for the development of lung fibrosis, and thus is involved in TGF- $\beta$ signaling (17). We evaluated $\alpha \mathrm{B}$-crystallin expression in $\mathrm{Ppl}^{/-}$and $\mathrm{Ppl}^{\mathrm{I}^{++}}$mice. In the basal condition, $\alpha \mathrm{B}$-crystallin (Cryab) mRNA levels were similar in $\mathrm{Ppl}^{-/}$and $\mathrm{Ppl}^{+/+}$mice. In response to bleomycin, Cryab mRNA levels were significantly reduced in $\mathrm{Ppl}^{-/-}$mice, compared with $\mathrm{Ppl}^{+/+}$mice at D7 (Figure 6A). IHC showed that, in normal condition, $\alpha \mathrm{B}$-crystallin protein was rarely detected in AECs in both genotypes (Figure 6B). Interestingly, $\alpha \mathrm{B}$-crystallin protein location was restricted to the perinuclear area in $\mathrm{Ppt}^{-/}$lungs, whereas it was mostly nuclear in $\mathrm{Ppl}^{+/+}$mice (Figure 6B). After bleomycin, we observed an increase in $\alpha \mathrm{B}$-crystallin nuclear localization in various cell types in $\mathrm{Ppl}^{+/+}$lungs and, to a lesser extent, in $\mathrm{Ppl}^{\mathrm{I}^{--}}$mice (Figure 6B). To determine whether $P p l$ deletion altered $\alpha \mathrm{B}$-crystallin expression, primary alveolar epithelial type 2 cells from $\mathrm{Ppl}^{+/+}$and $\mathrm{Ppl}^{\mathrm{H}^{--}}$mice were cultured in the absence (Ctrl) or in the presence of TGF- $\beta 1$ for 24 hours (Figure 6C). At baseline, Cryab mRNA levels were similar in both genotypes. In the presence of TGF- $\beta 1$, Cryab mRNA levels were markedly increased in $\mathrm{Ppl}^{+/+}$AEC2s but not in $\mathrm{Ppl}^{\mathrm{t}^{--}}$cells. These data support a profound alteration in the TGF- $\beta$ signaling in AECs in the absence of PPL, which may contribute significantly to the reduced fibrotic process observed in vivo.

Absence of PPL altered STAT3 activation and promoted Akt activation. Recent data also indicate that STAT3 contributes to the development of lung fibrosis as a regulator of TGF- $\beta$ transcriptional activity (18). STAT3 and P-STAT3 content in lung homogenates were assessed by Western blot in $\mathrm{Ppl}^{+/+}$and $\mathrm{Ppl}^{\mathrm{I}^{--}}$mice. In normal condition, similar expression of STAT3 and P-STAT3 was detected in $\mathrm{Ppl}^{+/+}$ 
A

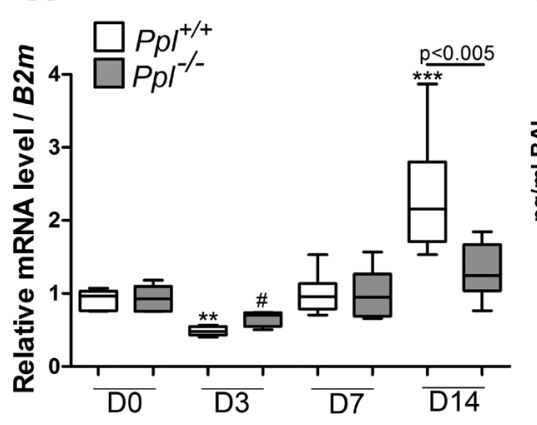

D

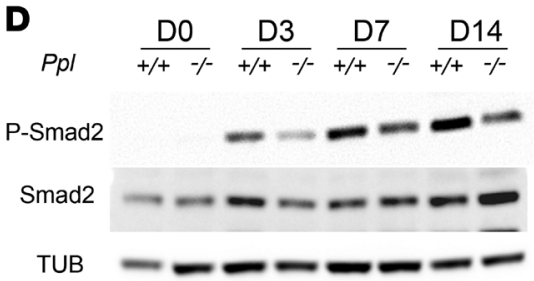

$\mathbf{F}$

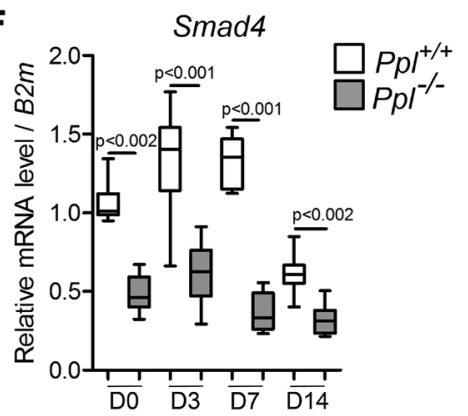

B

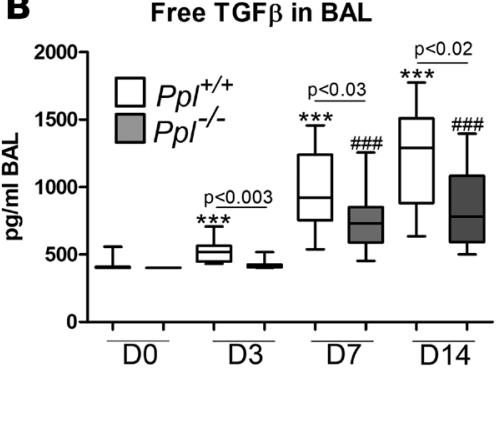

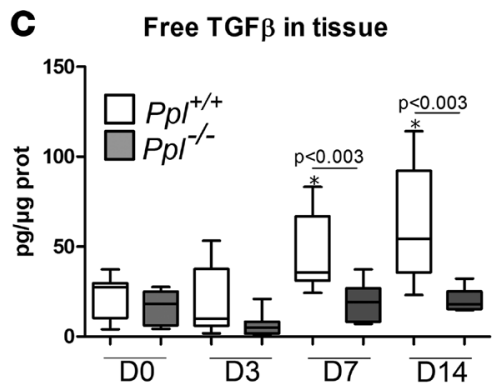

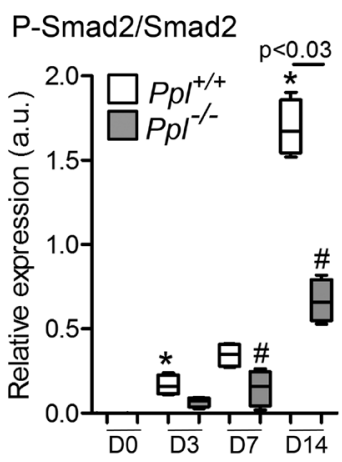

G

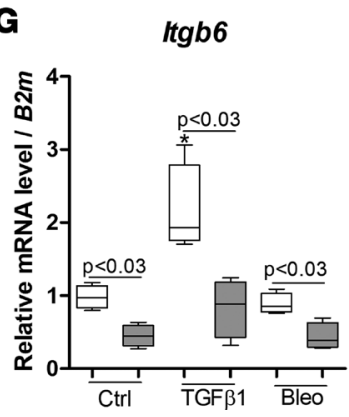

E

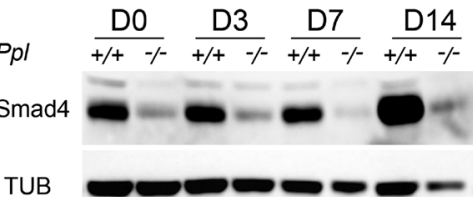

Smad4/TUB

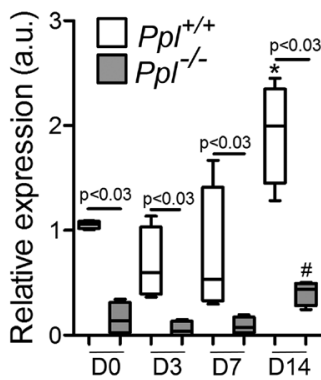

H

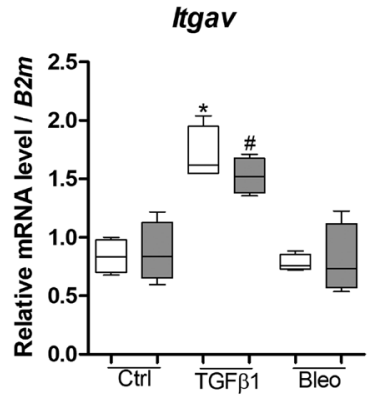

Figure 5. TGF- $\beta$ signaling was disturbed in $\mathbf{P p l}^{-/-}$mice. (A) qPCR was performed to evaluate $T g f b 1$ mRNAs in whole-lung homogenate from $P p l^{+/+}$mice after bleomycin instillation and normalized to $B 2 m$ mRNA. Results are expressed as means \pm SEM of 5 animals per group. Free TCF- $\beta 1$ concentration was assessed by ELISA in both BALF (B) and lung homogenates (C) of $\mathrm{Ppl}^{+/+}$and $\mathrm{Pp}^{-/-}$mice at indicated time points after bleomycin exposure in BALF. Data represent means \pm SEM. $n=7-9$ mice per group. (D) Immunoblotting for Smad2 and P-Smad2 was performed on $\mathrm{Pp}^{\mathrm{I}^{++}}$and $\mathrm{Ppl^{-/- }}$ lung homogenates on D0, D3, D7, and D14 after bleomycin instillation $(n=4)$. Histograms show a quantitative representation of P-Smad2/Smad2 ratios. (E) Immunoblotting for Smad4 was performed on $\mathrm{Ppl}^{+/+}$and $\mathrm{Ppl}^{-/-}$lung homogenates on DO, D3, D7, and D14 after bleomycin instillation ( $\left.n=4\right)$. Histograms show a quantitative representation of Smad4/TUB ratios. Densitometry results were expressed as arbitrary units. (F) qPCR was performed to evaluate Smad4 mRNAs in whole-lung homogenate from $\mathrm{Pp}^{l^{++}}$mice and normalized to $\mathrm{B} 2 \mathrm{~m}$ mRNA. Results are expressed as means $\pm \mathrm{SEM}$ of 5 animals per group. qPCR was performed to evaluate $\operatorname{ltgb6}(\mathbf{G})$ and $\operatorname{ltgav}(\mathbf{H})$ mRNAs in whole-lung homogenate from $\mathrm{Ppl}^{+/+}$mice and normalized to $B 2 \mathrm{~m}$ mRNA. Results are expressed as means \pm SEM of 5 animals per group. ${ }^{*} P<0.05$ vs. (DO, $\left.P p l^{+/+}\right) ;{ }^{* *} P<0.01 \mathrm{vs}$. (DO, $\left.P p l^{+++}\right) ;{ }^{* *} P<0.001 \mathrm{vs}$. (DO, $\left.P p l^{+++}\right) ;{ }^{\#} P<$ 0.05 vs. (DO, $\left.P \mathrm{pl}^{--}\right)$; \#\#\#<0.001 vs. (DO, P ${ }^{-{ }^{--}}$) Mann Whitney $U$ test.

and $\mathrm{Pp}^{\mathrm{L}^{--}}$mouse lung (Figure 7A). After bleomycin, P-STAT3 was increased from D3 to D14 in $\mathrm{Pp}^{\mathrm{l}^{++}}$ lungs, whereas only a transient and mild increase on D3 was noted in $\mathrm{Ppt}^{--}$lungs (Figure 7A). Immunostaining indicated that P-STAT3 was detected mainly in AECs, with a prominent nuclear staining; P-STAT3 immunostaining was decreased in $\mathrm{Ppt}^{-1-}$ lungs (Figure 7, B-I). To determine whether $P p l$ deletion altered Stat3 expression, P-STAT3 content was assessed by Western blot in MLE-15 cells deleted for the $P p l$ gene using CRISPR/Cas9 technology and cultured in the absence (Ctrl) or in the presence of TGF- $\beta 1$ for various times (Figure 7J). At baseline, P-STAT3 was decreased in $\mathrm{Ppl}^{-1-}$ MLE15 cells. In the presence of TGF- $\beta 1$, P-STAT3 levels were markedly increased in $P p l^{l^{++}}$MLE-15 cells but not in $\mathrm{Ppt}^{-/-}$MLE-15 cells. These data indicate that the absence of PPL is associated with an inhibition of STAT3 activation, which may have a direct effect on TGF- $\beta$ expression in this model. 
A

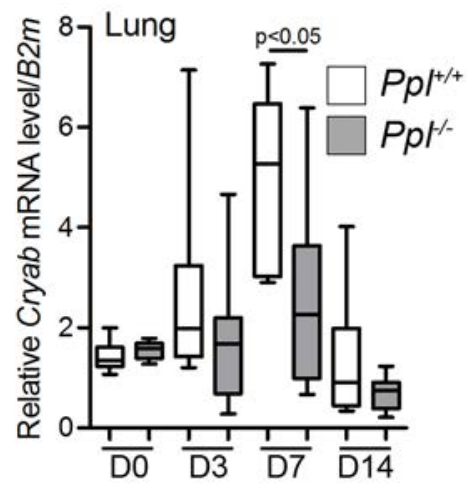

C

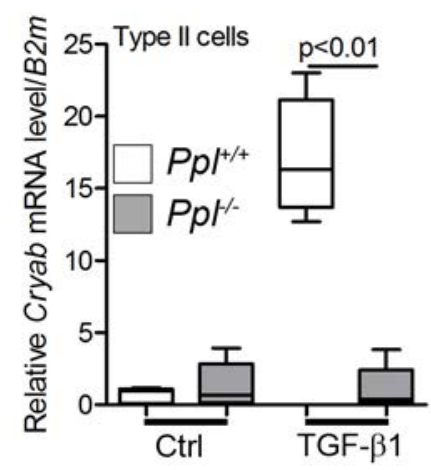

B

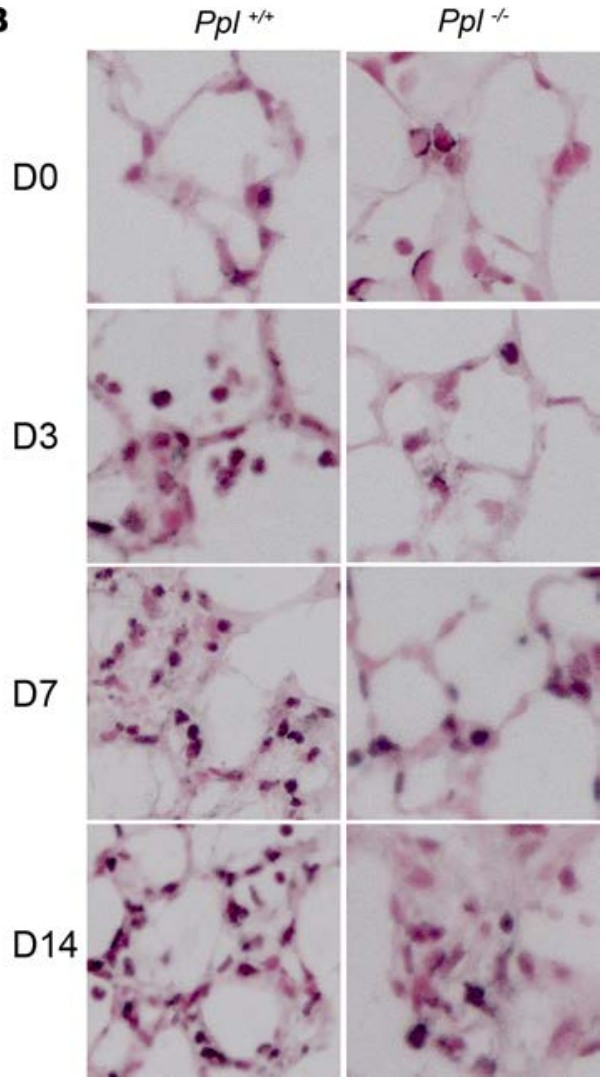

Figure 6. $\alpha \mathrm{B}$-crystallin expression was decreased after Ppl deletion. (A) qPCR was performed to estimate Cryab mRNA in whole-lung homogenate from $\mathrm{Ppl}^{+/+}$and $\mathrm{Ppl}^{-/-}$lung homogenates after bleomycin instillation and normalized to B2m mRNA. Results are expressed as means \pm SE of 5 animals per group. (B) $\alpha B$-crystallin expression was assessed by immunostaining in lung sections from $\mathrm{Pp}^{+/+}$and $\mathrm{Ppl}^{-/-}$mice after bleomycin instillation. This figure is representative of at least 6 individual mice at each time point. Magnification $\times 40$. (C) Cryab mRNA levels were estimated by qPCR in primary type $2 \mathrm{AECs}$ from $\mathrm{Ppl}^{+/+}$ and $\mathrm{Ppl}^{-/-}$mice in control conditions and in response to either bleomycin or TCF- $\beta 1$ and then normalized to $B 2 m$ mRNA. Results are expressed as means $\pm \mathrm{SE}$ of 5 animals per group; Mann Whitney U test.

PPL has been previously shown to interact with and modulate Akt localization and activity $(2,19)$. We measured Akt and P-Akt (S473) expression by Western blot in lung homogenates from naive or bleomycintreated $\mathrm{Ppl}^{+/+}$and $\mathrm{Ppl}^{-/-}$mice. We observed that, in normal condition (D0), P-Akt expression was increased in $P \mathrm{~F}^{-1-}$ lungs. After bleomycin, P-Akt expression was further increased in $\mathrm{Ppt}^{-1-}$ lungs on D3, compared with $\mathrm{Ppl}^{+/+}$mice (Figure 7K). By D7 and D14, P-Akt levels were similar in both groups.

Deletion of Ppl promoted an antiinflammatory alveolar environment. To better understand the mechanisms involved in reduced fibrosis in the absence of PPL, we next profiled the inflammatory cell infiltration in the lung in $\mathrm{Ppl}^{+/+}$and $\mathrm{Ppl}^{\mathrm{H}^{-}}$mice after bleomycin treatment (Supplemental Figure 1). Total cell counts were similar in $\mathrm{Ppl}^{+/+}$and $\mathrm{Ppl}^{-/-}$mice after bleomycin treatment (Figure 8A). Flow cytometric analysis showed that monocyte and neutrophil recruitment was reduced in $\mathrm{Ppl}^{{ }^{--}}$mice compared with $\mathrm{Ppl}^{+/+}$mice, while the resident alveolar macrophage population $\left(\mathrm{CD}^{+} 4^{+}, \mathrm{CD} 11 \mathrm{c}^{+}, \mathrm{CD} 206^{+}\right)$was increased (Figure 8B). No change in the inflammatory monocyte population $\left(\mathrm{CD}^{+} 4^{+}, \mathrm{Ly}_{6 \mathrm{C}^{+}}\right)$was observed (Figure 8B). Expression of Arg1 mRNA was reduced in BAL cells from $\mathrm{Ppl}^{-/-}$mice compared with $\mathrm{Ppl}^{+/+}$mice (Figure 8C). Within the resident alveolar macrophage population, a subpopulation of alternatively activated macrophages, characterized by a strong expression of arginase 1 (Arg $1^{\text {hi }}$ cell population) was reduced in $\mathrm{Ppl}^{-/-}$mice after bleomycin injury (Figure 8D). Cd206 mRNA levels were similar in both genotypes (Figure 8E).

Next, we investigated the expression of a panel of pro- and antiinflammatory mediators in BALF. Expression of CCL21 and CXCL16, two chemokines known to play a role in fibrogenesis $(20,21)$, were significantly reduced in the BALF from $\mathrm{Ppl}^{-/-}$mice as compared with $\mathrm{Ppl}^{+/+}$mice following bleomycin challenge (Figure 8, F and G). Expression of other chemokines, including CCL2, CCL8, and CCL12, was similar in $\mathrm{Ppl}^{+/+}$and $\mathrm{Ppl}^{-/-}$mice in normal conditions and after bleomycin challenge (Supplemental Figure 5). By contrast, IL-10 and IL-1ra, two antiinflammatory molecules, were readily detected in the BALF of $\mathrm{Ppt}^{-1-}$ naive mice, while IL-1ra was reduced and IL-10 was below the limits of detection in $\mathrm{Ppl}^{+/+}$mice (Figure 8, I and J). After bleomycin treatment, IL-10 was significantly increased in the BALF of $\mathrm{Ppl}^{-/-}$mice compared with $\mathrm{Ppl}^{t^{++}}$mice. Interestingly, chemerin, a cytokine known to inhibit M2 macrophage polarization (22) and associated with the resolution of acute inflammation in the lung (23-25), was significantly increased on D3 and D7 in the BALF of $\mathrm{Ppl}^{-1-}$ mice compared with $\mathrm{Ppl}^{+/+}$mice (Figure $8 \mathrm{H}$ ). Altogether, these data indicate that PPL deletion induced an 

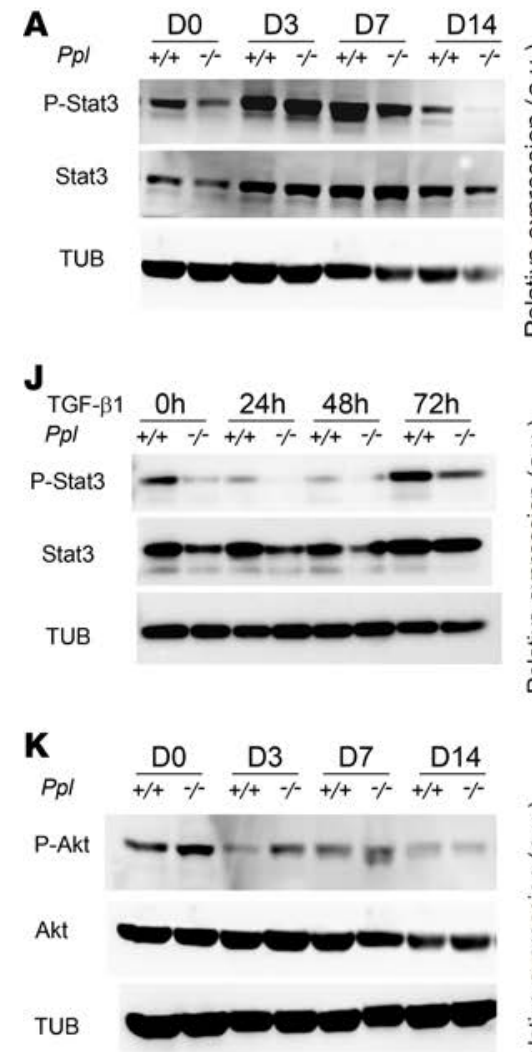
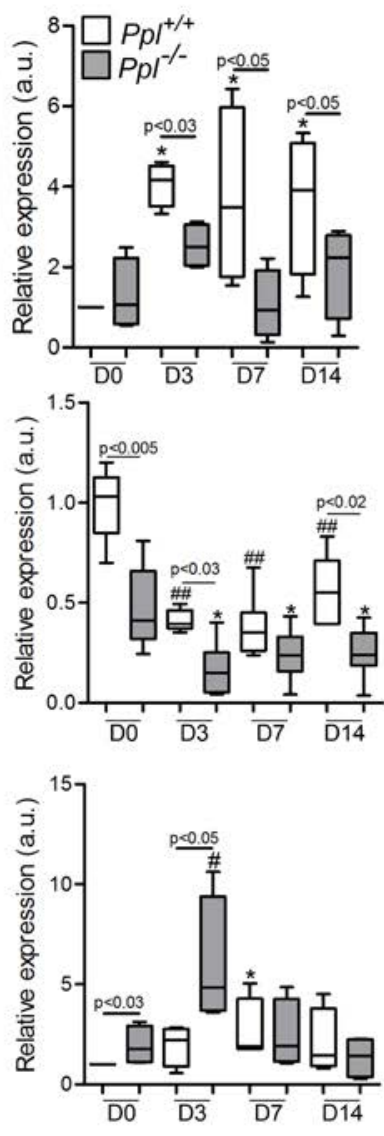

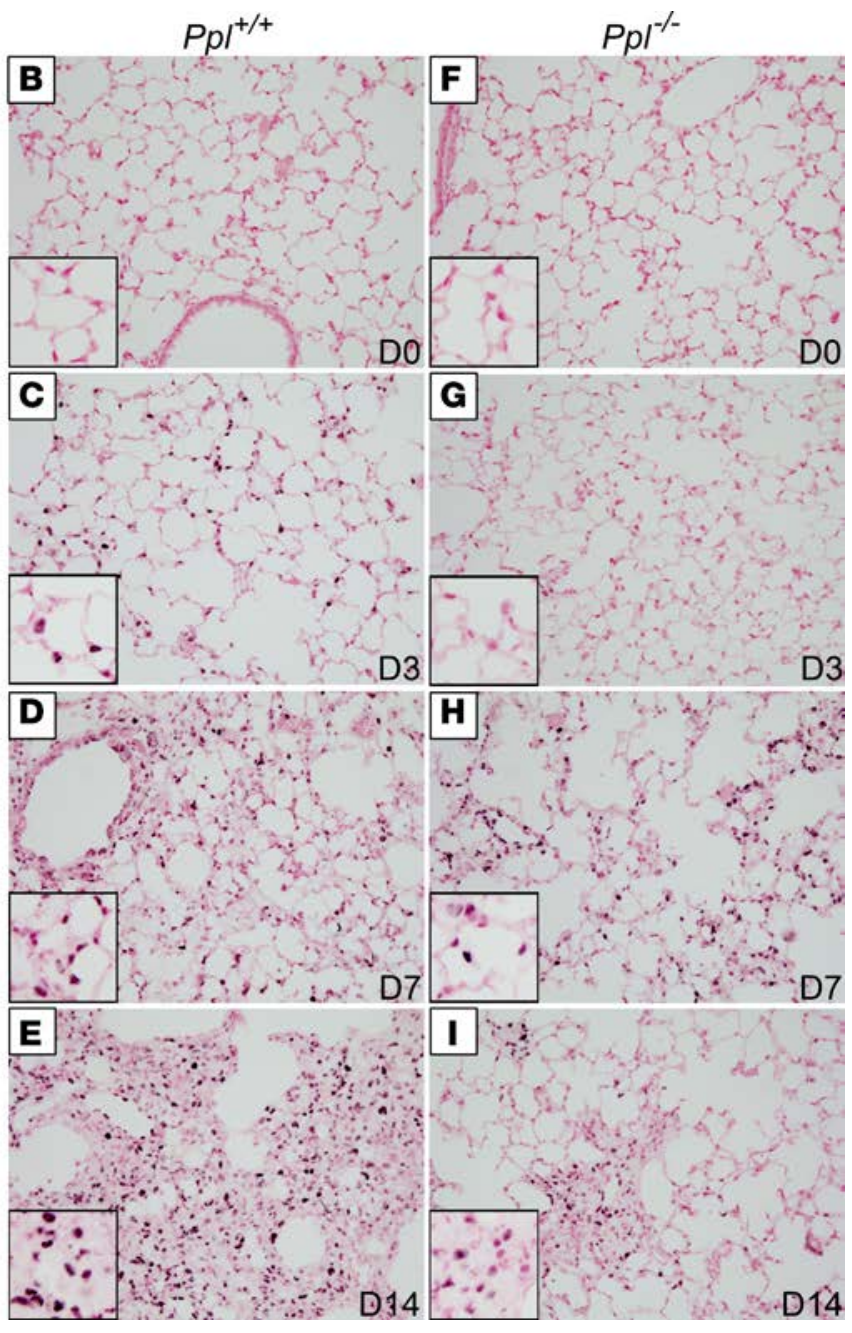

Figure 7. Cell signaling was disturbed in $\mathbf{P p l}^{/_{-/}}$mice. (A) Immunoblotting for STAT3 and P-STAT3 (Tyr705) was performed on $\mathrm{Ppl}^{+/+}$and $\mathrm{Ppl}^{\mathrm{I}^{-/}}$lung homogenates at D0, D3, D7, and D14 after bleomycin instillation $(n=4)$. Histograms show a quantitative representation of P-STAT3/ STAT3 ratios. (B-I) P-STAT3 expression was assessed by immunostaining in lung sections from $\mathrm{Ppl}^{+/+}$and $\mathrm{Ppl}^{-/-}$mice after bleomycin instillation. Figure is representative of at least 6 individual mice at each time. Magnification $\times 40$. (J) Immunoblotting for STAT3 and P-STAT3 (Tyr705) was performed on CRISPR-Cas9 periplakin deleted $\left(P \mathrm{~F}^{-/-}\right)$or WT $\left(P \mathrm{Pl}^{+++}\right)$MLE-15 cells exposed to TCF- $\beta 1$ for 24,48 , or 72 hours. The Western blot is representative for 3 different experiments. Quantitative evaluation of the Western blots for each time point is shown. (K) Immunoblotting for AKT and P-AKT (Ser473) was performed on $\mathrm{Ppl}^{{ }^{+/+}}$and $\mathrm{Ppl^{-/- }}$ lung homogenates on DO, D3, D7, and D14 after bleomycin instillation $(n=4)$. Histograms show a quantitative representation of P-Akt/Akt protein ratio.

antiinflammatory environment in the lung.

We extended the whole-lung BALF observations and assessed the impact of the loss of PPL on AEC spontaneous mediator release, with chemerin, IL-10, and IL-1ra being assessed in the supernatant of primary AEC2s from $\mathrm{Ppl}^{-/-}$and $\mathrm{Ppl}^{+/+}$mice (Figure 9, A-C). Chemerin and IL-10 concentration were increased in $\mathrm{Ppt}^{{ }^{-1}}$ supernatants, while IL-1ra concentration was similar in both groups. To confirm these results, mRNA levels of Rarres2, Il10, and Illra were assessed by qPCR in MLE-15 cells deleted for the Ppl gene using CRISPR/Cas9 technology (Figure 9, D-F). Rarres2, Il10, and Illra mRNAs were increased in Ppt ${ }^{-1}$ MLE-15 cells compared with $\mathrm{Ppl}^{+/+}$MLE-15 cells. These data indicate that the absence of PPL disturbs cytokine expression in AECs and promotes the expression of antiinflammatory mediators associated with tissue repair.

\section{Discussion}

Our study identifies the regulatory role of PPL in lung injury and repair. We first demonstrated that PPL expression was decreased after bleomycin-induced lung injury through the action of multiple mediators, including TGF- $\beta 1$, and the coordinated action of 2 transcription factors, Klf5 and Egr2. Deletion of the $P p l$ gene in mice improved survival and reduced lung fibrosis development after bleomycin-induced injury. Notably, $P p l$ deletion promoted an antiinflammatory alveolar environment linked to profound changes 


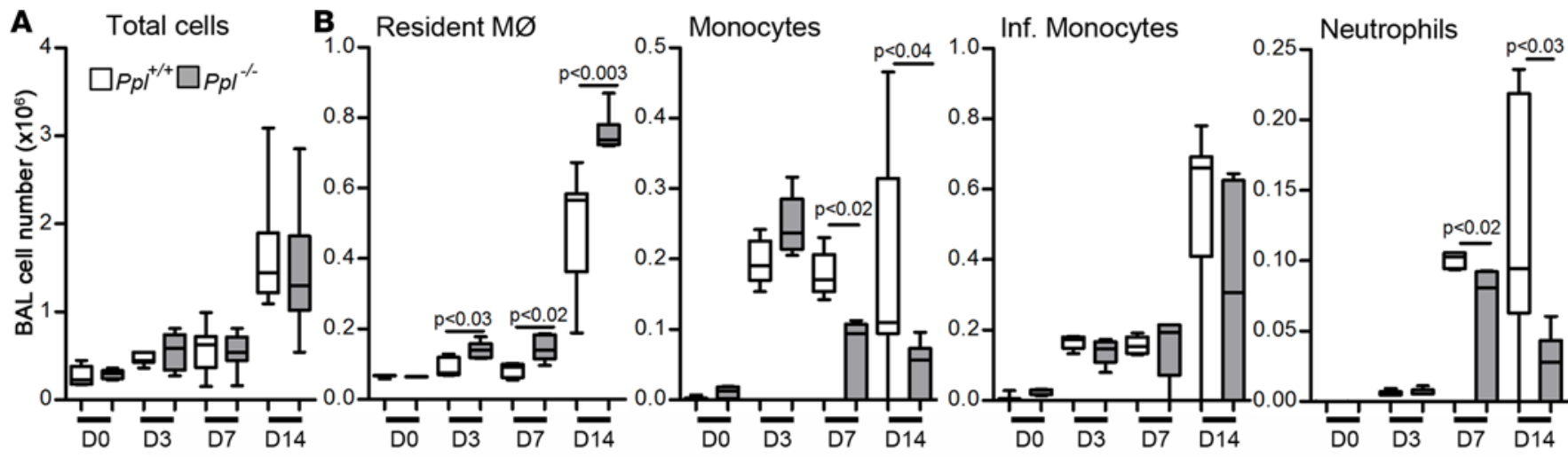

C
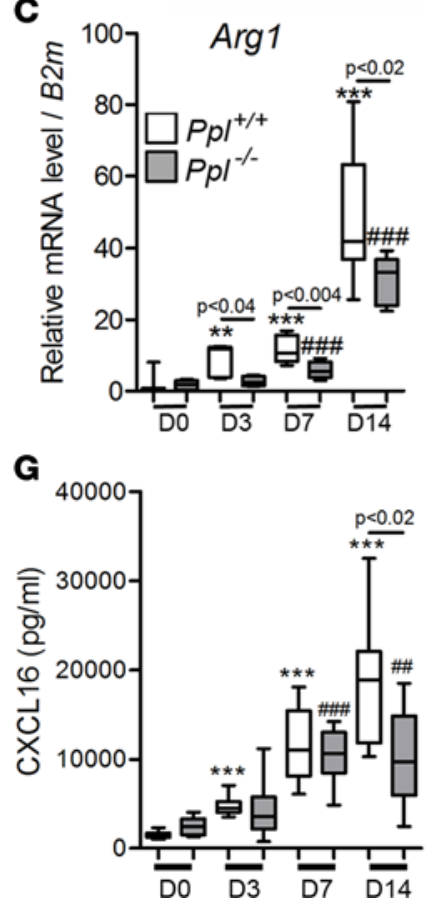

D

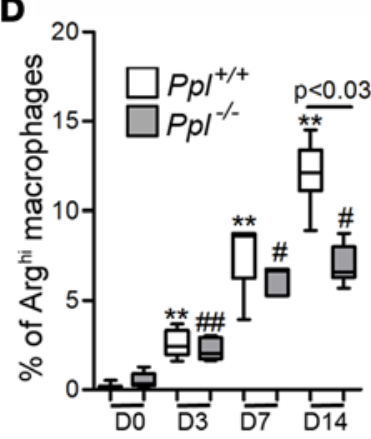

H

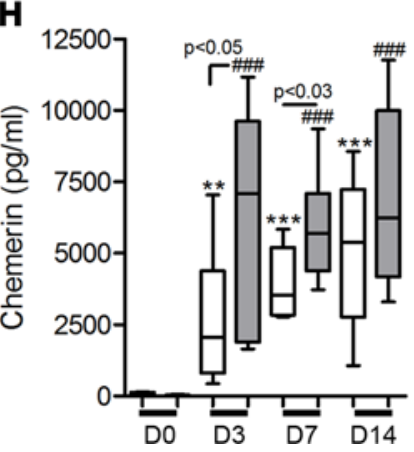

E

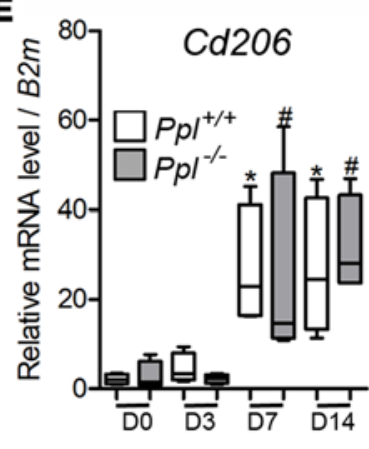

I

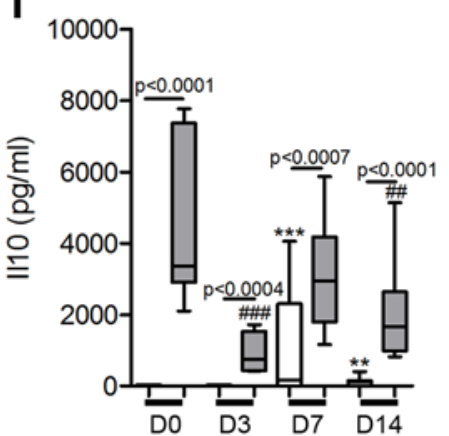

$\mathbf{F}$
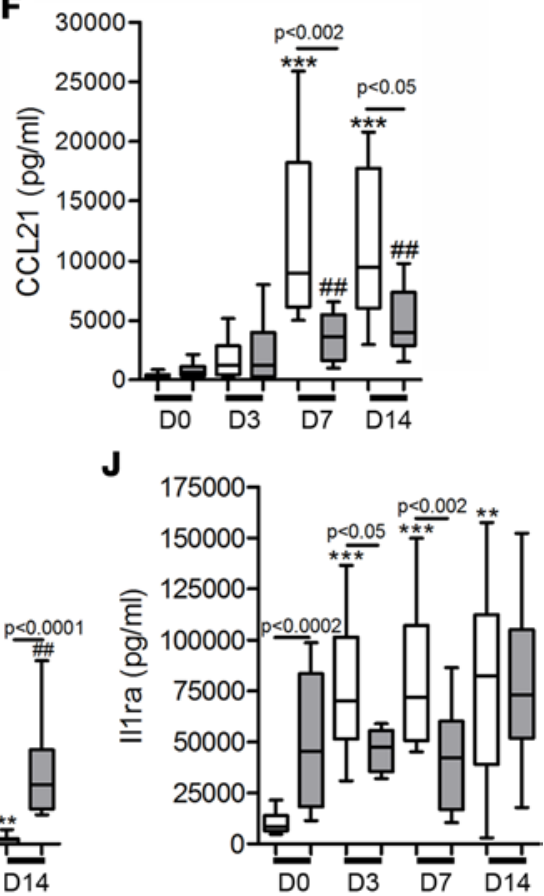

Figure 8. Inflammatory cell recruitment was modified in $\mathrm{Ppl}^{\mathrm{I}^{-/}}$mice. (A) Total cell count was determined in BAL from $\mathrm{Pp}^{+/+}$and $\mathrm{Ppl}^{-/-}$mice after bleomycin exposure. Changes in BAL cell population for mouse groups are shown. (B) Resident macrophage, monocyte, neutrophil, and inflammatory monocyte populations (as defined in Methods) were calculated by flow cytometry for each indicated time point after bleomycin instillation. (C) Arg1 mRNA levels were estimated by qPCR in BAL alveolar macrophages from $\mathrm{Ppl}^{+/+}$and $\mathrm{Ppl}^{-/-}$mice at indicated time points after bleomycin exposure. (D) Percentage of

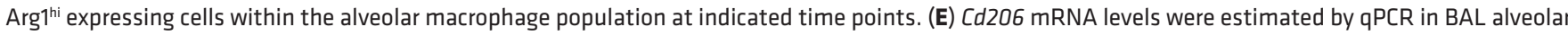
macrophages from $\mathrm{Ppl}^{+/+}$and $\mathrm{Pp}^{-/-}$mice at indicated time points after bleomycin exposure. Proinflammatory CCL21 (F), CXCL16 (C), antiinflammatory chemerin (H), IL-10 (I), and IL-1ra (J) cytokine concentration was assessed by ELISA in BALF of $P \mathrm{pl}^{+/+}$and $P \mathrm{pl}^{-/-}$mice at indicated time points after bleomycin exposure. Data represent means \pm SEM $n=7-9$ mice per group. ${ }^{*} P<0.05$ vs. (DO, $P p l^{+++}$); ${ }^{* *} P<0.01$ vs. (DO, $\left.P p l^{+++}\right) ;{ }^{* * *} P<0.001$ vs. $\left(\mathrm{DO}, P p l^{+++}\right)$; $P<0.05$

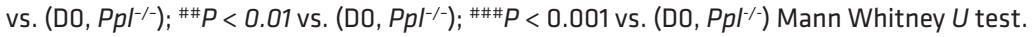

in $\mathrm{AEC} 2 \mathrm{~s}$, including overexpression of antiinflammatory cytokines, decreased expression of profibrotic mediators, and altered cell signaling with a reduced response to TGF- $\beta 1$. Our results point to a role for PPL as a controller of lung inflammation and fibrogenesis and suggest that the early and sustained decrease of PPL expression observed during lung injury might be a protective mechanism, allowing for an antiinflammatory and prorepair shift in the epithelial cell phenotype.

During the past years, different groups have identified the possible role of junctional proteins in the pathophysiology of pulmonary fibrosis. In a previous study from our laboratory, Taillé et al. reported that PPL was relocated to the apex of epithelial cells in the remodeled alveolar epithelium cells in IPF patients and that PPL was the target of an autoimmune response (7). Likewise, a genome-wide association study associated the desmoplakin gene, another desmosomal protein, with IPF (9). Recently, Mathai et al. identified desmoplakin sequence variants associated with differential expression of desmoplakin in the lungs of 
A

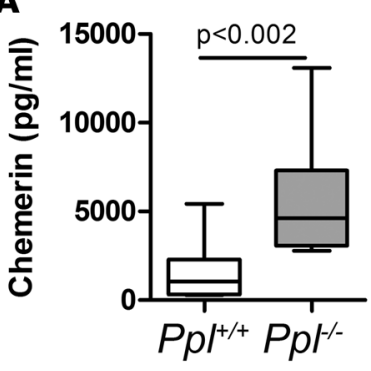

B

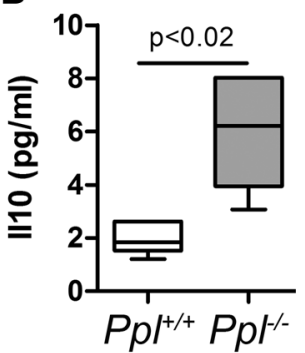

C

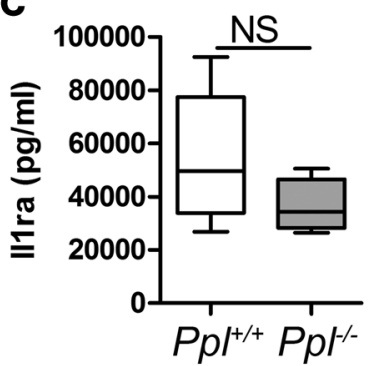

Figure 9. Spontaneous antiinflammatory cytokine expression was increased in AECs from $\mathrm{Ppl}^{-/-}$mice. Chemerin (A), IL-10 (B), and IL-1ra (C) levels were measured by ELISA in primary type 2 AECs culture supernatants after 48 hours of culture from $\mathrm{Ppl}^{+/+}$ and $P p^{-1-}$ mice. $n=5$. Mann Whitney $U$ test. qPCR for Rarres2 (D), I/10 (E), and I/1ra (F) mRNA was performed on CRISPR-Cas9 periplakin deleted $\left(\mathrm{Ppl}^{-/-}\right)$ or WT $\left(\mathrm{Ppl}^{+/+}\right) \mathrm{MLE}-15$ cells exposed to TGF- $\beta 1$ for 24 hours. $n=5$; Mann Whitney $U$ test.
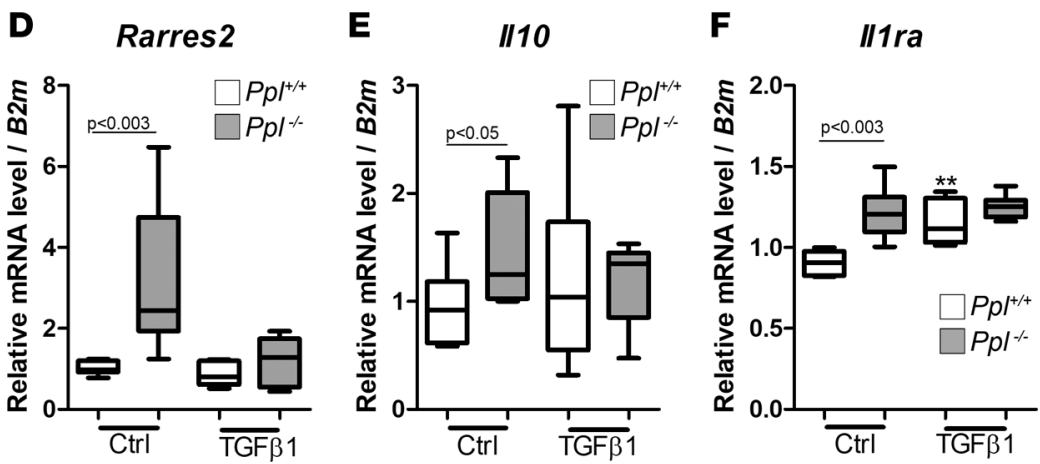

IPF patients (10). Given the emerging link between desmosomal proteins and IPF, we investigated the potential role of PPL in a murine model of lung fibrosis induced by bleomycin. We initially hypothesized that $\mathrm{Ppl}^{-1-}$ mice would present a more severe phenotype following bleomycin, due to a potential loss of epithelial integrity and a worsening of acute lung injury. However, remarkably, $\mathrm{Ppl}^{-1-}$ mice had an improved survival with reduced subsequent lung fibrosis. Absence of PPL was not compensated through the altered level of other desmosomal genes or other cell junction components (including envoplakin, desmoplakin, involucrin, plectin, and kazrin) (Supplemental Figure 6). These observations suggest that the primary function of PPL in the lung is not related to the maintenance of cell junction but is rather involved in orchestrating the response to injury. Interestingly, although $\mathrm{Ppt}^{-1}$ mice have a normal dermal layer, mice deficient in involucrin, envoplakin, and PPL have a minor defect in epidermal barrier function (26).

To determine the potential signaling pathways associated with PPL and epithelial injury, we profiled the promoter region of PPL. Interestingly we identified 2 transcription factors that control PPL expression in the lung, Klf5 and Egr2. Klf5 is required for perinatal lung maturation and the expression of many genes essential for lung function (27). Inhibition of Klf5 expression has been shown to be a master event in the development of skin and lung fibrosis in mice (28). Egr2 is a functionally distinct transcription factor that is both necessary and sufficient for TGF- $\beta$-induced profibrotic responses, and it is aberrantly expressed in lesional tissue in systemic sclerosis and in a murine model of scleroderma (29). Here, we show for the first time to our knowledge that TGF- $\beta$ controls the expression of $P p l$ through the regulated expression of Klf5 and Egr2. Finally, alveolar type 2 cells isolated from $\mathrm{Ppl}^{-1-}$ mice appeared to be resistant to TGF- $\beta$ stimulation in vitro. Our results indicate that this could be linked to a decreased expression of Smad4, a regulator of the TGF- $\beta$ canonical pathway, and the decreased expression of $\alpha \mathrm{B}$-crystallin, a member of the small heat shock protein family that interacts with intermediate filaments in response to stress $(30,31)$. In $\mathrm{Ppt}^{-1-}$ mice, $\alpha \mathrm{B}$-crystallin expression was reduced, and its nuclear localization was delayed. Recently, Bellaye et al. demonstrated that mice deleted for $\alpha \mathrm{B}$-crystallin were protected from bleomycin-induced lung fibrosis $(17,32)$ and that $\alpha B$-crystallin was capable of interacting with Smad4 and facilitated Smad4 nuclear localization and activity. These data suggest that PPL controls the activation of the TGF- $\beta$ pathway at different cellular levels, likely through its interaction with intermediate filaments.

The protection against fibrosis development in $\mathrm{Ppl}^{\mathrm{H}^{-}}$mice was associated with a fundamental change of the lung and AEC response to injury, with a blunted inflammatory response, a decrease in inflammatory cell recruitment, a change in macrophage phenotype, and the preferential production of antiinflammatory molecules such as IL-10, IL-1ra, and chemerin. Expression of Tgfb1, a potent mediator of lung fibrosis, was decreased on D14, consistent with reduced collagen content in the lungs of $\mathrm{Ppl}^{-1-}$ mice. Similarly, CCL21 and CXCL16 were reduced in the BALF from $\mathrm{Ppt}^{-1-}$ mice. CCL21 and CXCL16 are two chemokines known 
to play a role in fibrosis either by triggering migratory and proliferative responses in lung fibroblasts (21, 33 ) or by promoting fibrocyte recruitment $(34,35)$. Interestingly, except for CCL21 and CXCL16, no significant differences were observed for most inflammatory cytokines we analyzed either at the mRNA levels (Tnfa, Il1b, Il6, Cxcl1) (Supplemental Figure 6) or at the protein levels (CCL2, CCL8, CCL12).

Along with having attenuated proinflammatory cytokines in the fibrotic lung, $\mathrm{Pp}^{1-}$ mice exhibited a heightened antiinflammatory environment at baseline and in response to bleomycin. The antiinflammatory cytokines IL-10 and IL-1ra were increased in the BAL of $\mathrm{Ppt}^{-1-}$ mice in normal conditions. Elevated IL-10 expression persisted after bleomycin injury in $\mathrm{Ppt}^{--}$mice. IL-10 is an immunosuppressive cytokine that inhibits the production of many proinflammatory cytokines (36). IL-10 also has antifibrotic functions, as it reduces the production and activation of TGF- $\beta$ in the lung $(37,38)$. In addition, we observed that chemerin was significantly increased in $\mathrm{Ppt}^{-1-}$ mice. Chemerin has been shown to be involved in various processes associated with inflammation (39). In the lung, chemerin displays antiinflammatory properties, including reduced neutrophil and monocyte recruitment in various models of lung injury, such as those induced by LPS (25), cigarette-smoke (24), and acute viral pneumonia (23). In the current study, we also observed a decrease in neutrophil and monocyte recruitment to the lung in parallel with a significant increase of chemerin in $\mathrm{Ppl}^{\mathrm{t}^{-}}$mice. The source of the antiinflammatory cytokines is both epithelial and nonepithelial. The increase in IL-1ra in the $\mathrm{Ppt}^{-1-}$ bleomycin-challenged lung is likely not from epithelial cells, as we saw no difference in epithelial IL-1ra release in vitro. In contrast, both IL-10 and chemerin were released in spontaneously greater quantities from $\mathrm{Ppt}^{/-}$epithelial cells compared with $\mathrm{Ppl}^{\mathrm{t}^{++}}$mouse-derived epithelial cells.

Lung injury seen following bleomycin comprises an interstitial edema with an influx of inflammatory and immune cells. In $\mathrm{Ppt}^{-1-}$ lungs, monocyte and neutrophil recruitment was decreased, while resident macrophage number was increased. Further characterization indicated that macrophages recruited in $P p l$ /- lungs expressed less Arg1 and that the number of Arg1 $1^{\text {hi }}$ expressing macrophages was reduced in $\mathrm{Ppl}^{-1}$ mice. Expression of Arg1 is a key hallmark of M2-like or alternatively activated macrophages in mice. M2 macrophages are increased in pulmonary fibrosis and are associated with fibrosis development (40). Reduction in Arg1 expression in alternatively activated macrophages might be due to the high levels of chemerin in the BAL. Indeed, in the digestive tract, Lin et al. showed that chemerin did not alter inflammatory cell recruitment but decreased the expression of M2 macrophage-associated genes, including Arg1, following dextran sulfate sodium exposure, suggesting an impaired M2 macrophage fate in vivo (22). Collectively, the bleomycin-induced increase in chemerin from epithelial cells in $\mathrm{Pp}^{-1-}$ mice may directly modulate newly recruited monocytes and/or resident monocyte/macrophages away from the profibrotic M2 macrophage.

Following the antifibrotic phenotype that we observed in the $\mathrm{Pp}^{\mathrm{I}^{-1}}$ mice, we also assessed the impact of PPL deletion on 2 other signaling pathways associated with inflammation and, more recently, associated with fibrosis, Akt, and STAT3. van den Heuvel and colleagues previously showed a possible role for PPL as a localization signal in Akt-mediated signaling (2). Interestingly, in the current study, we observed that activation of Akt (P-Akt [Ser473]) was increased in $\mathrm{Ppt}^{-1-}$ mice in basal conditions. Therefore, the control of Akt activation might be a major function of PPL. In cells, endogenous PPL localizes to different cellular compartments, including plasma membrane, intermediate filament structures, the nucleus, and mitochondria. In vitro experiments performed with different epithelial cell lines (MCF-7, HeLa) indicate that PPL is required for the reorganization of the keratin intermediate filaments network at the wound edge of simple epithelial cell monolayers and that the absence of PPL impairs wound closure in vitro (41). Similar data have been observed in vitro in squamous cancer cells, where PPL downregulation reduced cellular motility and Akt activation (19). Akt activation in $\mathrm{Ppt}^{--}$mice might also be due to the binding of chemerin to its main receptor ChemR23, whose activation leads to the upregulation of the phosphatidylinositol 3-kinase/ Akt signaling pathway and to downregulation of NF- $\mathrm{kB}(42)$.

Our data also indicate that PPL controls STAT3 activation. In $\mathrm{Ppl}^{-1-}$ mice, activation of Stat3 was reduced after bleomycin injury during both the inflammatory and fibrotic phase. IHC experiments showed a delayed activation of Stat3 in AECs and less P-Stat3 in fibrotic areas in $\mathrm{Ppt}^{-1-}$ mice. Stat 3 activation has been implicated in the fibrotic lung in patients with IPF and in bleomycin-induced lung fibrosis in mice (18, 43). Alterations in the inflammatory environment of the lung in $\mathrm{Pp}^{-/}$mice may have caused the decrease in STAT3 activation. However, Pedroza et al. showed that C-188-9, a STAT3 inhibitor, decreased lung fibrosis through a decrease of epithelial injury and fibroblast-to-myofibroblast differentiation (18). Therefore, it would be interesting to see if PPL expression is altered in bleomycin-challenged mice during STAT3 inhibition in order to confirm the hierarchy of this pathway. 
In summary, the present study identified PPL as a master regulator of the lung response to injury in a murine model of lung fibrosis, modifying numerous pathways associated with epithelial activation and subsequent fibrotic responses. Moreover, a thorough understanding of the signaling pathways directly controlled by PPL and the role of epithelial responses will promote our understanding of the pathogenesis of lung fibrosis.

\section{Methods}

Animal husbandry and bleomycin administration. $\mathrm{Pp}^{\mathrm{H}^{--}}(\mathrm{C} 57 \mathrm{BL} / 6 \mathrm{~J})$ mice were generated as described previously (13). For genotyping, DNA was purified from the tail of experimental mice, and PCR was performed for $P p l$ and $P G K$ promoter-specific genes (13). WT $\left(\mathrm{Ppl}^{+/+}\right)$mice (Janvier Labs) were used as control mice for the experiments. All animals were housed in humidity- and temperature-controlled rooms on a 14:10hour light-dark cycle. Mice were allowed food and water ad libitum. There was no serological evidence of pulmonary pathogens in sentinel mice maintained within the colony. All experiments were performed with adult male mice. On D0, mice were administered $55 \mu$ g of intratracheal bleomycin hydrochloride (Bleomycin Bellon, Aventis) or vehicle (0.9\% sterile saline), in a volume of $50 \mu 1$. Animals were sacrificed on D0, D3, D7, or D14 after instillation.

Ad-TGF- $\beta 1$-induced lung fibrosis. Ad-TGF- $\beta 1$ or control virus (Ad-Ctrl) were a gift of Martin Kolb (McMaster University). Mice received $2 \times 10^{8} \mathrm{PFU}$ in $50 \mu \mathrm{l}$ sterile saline intratracheally and were sacrificed 28 days after instillation.

Tissue preparation, histology, and IHC. Body weight data were collected at the time of death. Mice were first weighed and then killed by an injection of $0.25 \mathrm{ml}$ of anesthetic (ketamine, xylazine) (Sigma) and exsanguinated. Lungs were inflation fixed in 4\% paraformaldehyde in PBS (20 mM Tris HCl, pH 7.6, 137 $\mathrm{mM} \mathrm{NaCl}$ ) at $25 \mathrm{cmH}_{2} \mathrm{O}$ before immersion. Lungs were fixed overnight, washed with PBS, dehydrated in a series of alcohols, and embedded in paraffin. Tissue sections were stained with H\&E. In addition, IHC was performed on tissue sections by a microwave antigen-retrieval technique for PPL, P-Stat3, and $\alpha \mathrm{B}$-crystallin. Sections were pretreated with $3 \% \mathrm{H}_{2} \mathrm{O}_{2}$ in methanol for inactivation of endogenous peroxidase and then blocked in $4 \%$ normal horse serum for 2 hours before incubation with the primary antibody overnight at $4^{\circ} \mathrm{C}$. Antibodies used were generated to: PPL (1:500, goat polyclonal, Santa Cruz Biotechnology Inc.; sc16754), collagen type 1 (1:200, rabbit polyclonal, Abcam; ab34710), collagen type 3 (1:200, rabbit polyclonal, Abcam; ab7778), aB-crystallin (1:500, rabbit polyclonal, Abcam; ab13497), and P-Stat3 (1:500, rabbit polyclonal, Cell Signaling Technology; D3A7). After being rinsed, tissue sections were incubated with either biotinylated horse anti-goat IgG or biotinylated goat anti-rabbit IgG $(7.5 \mu \mathrm{g} / \mathrm{ml}$; Vector Laboratories) for 30 minutes and detected with an avidin-biotin peroxidase complex detection kit (Vectastain Elite ABC kit; Vector Laboratories) using nickel-diaminobenzidine as a substrate. The precipitation reaction was enhanced with Tris-cobalt, and the sections were counterstained with $0.1 \%$ of nuclear fast red. All experiments shown are representative of findings from at least 4 independent experiments.

$B A L F$. After treatment, mice ( $n=5$ /group) were anesthetized and killed as described above. Tracheas were cannulated, and five $1-\mathrm{ml}$ aliquots of $0.9 \% \mathrm{NaCl}$ were flushed into the lungs and withdrawn by syringe 3 times for each aliquot. The volumes of recovered BALF from all the groups were similar. After centrifugation, BAL cells were counted using a hemocytometer to determine total BAL cell concentration. BAL cells were used for RNA extraction, or - after cytospin — cells were stained to determine differential cell counts (Diff-Quik, Dade Behring).

Isolation of alveolar epithelial type 2 cells. AEC2 were isolated from adult $\mathrm{Ppl}^{-{ }^{--}}$and $\mathrm{Ppl}^{+/+}$mouse lung with use of dispase and differential plating, as described previously (44). AEC2 were stimulated for 24 and/or 48 hours by either human BAL or the following recombinant proteins $(10 \mathrm{ng} / \mathrm{ml})$ : human TGF- $\beta 1$ (hTGF- $\beta 1$ ), hPDGF-BB, hTNF $\alpha$, and IL-1 $\beta$ (R\&D Systems).

MLE-15 cell culture. MLE-15, an immortalized mouse lung epithelial cell line that maintains some morphological and functional characteristics of AEC2, were cultured in hydrocortisone, insulin, transferrin, estradiol and selenium (HITES) medium (45). MLE-15 cells were stimulated for 24 and/or 48 hours by either human BAL or the following recombinant proteins (10 ng/ml): hTGF- $\beta 1$, hPDGF-BB, hTNF $\alpha$, and IL-1 $\beta$ (R\&D Systems).

Cell transfection. Cells were transfected with the Lipofectamine 2000 transfection reagent (Invitrogen) according to the manufacturer's protocol. The expression vectors used were the following: pCMV5-K1f5, provided by J.A. Whitsett (Cincinnati, Ohio, USA), and pcDNA3-mEgr2 (described in this paper). Mouse Egr2 cDNA encoding amino acids $1-470$ was cloned by PCR amplification into pcDNA3.1 (Invitrogen). 
Insertion of murine Egr2 ( $m E g r 2)$ into pcDNA3 was confirmed by sequencing.

Ppl gene deletion in MLE-15 cells was done using the Crisp/Cas9 technology. MLE-15 cells were cotransfected with PPL CRISPR/Cas9-KO plasmid (sc 422373, Santa Cruz Biotechnology Inc.) and PPL HDR Plasmid (sc 422373-HDR, Santa Cruz Biotechnology Inc.). Cell selection was performed using puromycin (5 $\mu \mathrm{g} / \mathrm{ml}$ ) for 2 weeks. Stably deleted cells were maintained in HITES medium containing puromycin.

$R N A$ extraction and reverse transcription PCR. RNA was extracted from whole-lung homogenate of $\mathrm{Ppt}^{-1-}$ and $\mathrm{Ppl}^{+/+}$mice or isolated lung AEC2s or BAL cells of adult mice with use of Trizol reagent according to the manufacturer's protocol. qPCR using Sybr Green (Applied BioSystems) was performed with specific primer sets (Primer sets in Supplemental Table 1). A probe set for b2-microglobulin (B2m) was used as the normalization standard. The PCR and relative quantifications were performed in a real-time PCR system (model Fast7500, Applied BioSystems).

Flow cytometry analysis and sorting. BAL cells from mice instilled with either saline solution or bleomycin were fixed and permeabilized using cytofix/cytoperm buffer (R\&D Systems). Flow cytometry (Canto II, BD Biosciences) was performed on fixed $0.5 \times 10^{6} \mathrm{BAL}$ cells, after incubation with $50 \mu \mathrm{l}$ of Fc block anti-mouse CD16/CD32 (BD Pharmingen) on ice for $15 \mathrm{~min}$, followed by staining with anti-mouse antibodies (Supplemental Table 2) according to manufacturer's protocols, as well as their isotype controls. Biotinylated antibody-antigen complexes were detected using streptavidin conjugated with Brilliant violet 421 (BioLegend). FACS data were analyzed using Flow Jo 9.5. After gating out debris and neutrophils $\left(\mathrm{F} 480^{\mathrm{lo}} \mathrm{CD} 11 \mathrm{~b}^{\mathrm{hi}}\right)$, monocytes and macrophages were analyzed using a CD64 gate. Resident and recruited

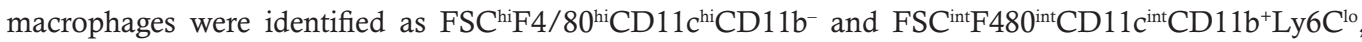
respectively. Inflammatory monocytes were defined as $\mathrm{F} 480^{\mathrm{lo}} \mathrm{CD} 11 \mathrm{~b}$ hy $6 \mathrm{C}^{\text {hi }} \mathrm{CD} 11 \mathrm{c}^{-}$. Gating strategy is described in Supplemental Figure 1A.

Western blot analysis. Protein expression was quantified by Western blot analysis in whole-lung homogenate. Proteins were extracted by addition of lysis buffer $(250 \mathrm{mM} \mathrm{NaCl}, 50 \mathrm{mM}$ HEPES pH 7.0, $5 \mathrm{mM}$ EDTA, $1 \mathrm{mM}$ dithiothreitol [DTT], 0.1\% nonidet NP40, $10 \mu \mathrm{g} / \mathrm{ml}$ aprotinin, $10 \mu \mathrm{g} / \mathrm{ml}$ leupeptin, $50 \mu \mathrm{g} /$ $\mathrm{ml}$ phenylmethylsulfonyl fluoride, $2 \mathrm{mM}$ sodium pyrophosphate, and $1 \mathrm{mM}$ sodium orthovanadate), diluted in Laemmli buffer, and subjected to SDS-PAGE under reducing condition. Immunostaining was performed with specific antibodies (Supplemental Table 2) according to manufacturer's protocols.

Quantification of soluble collagen. For quantification of total soluble collagen, Sircol assay was performed according to manufacturer's instructions (Biocolor) using the pepsin digestion step described by Lareu et al. (46). To minimize background due to the interference of serum proteins with the Sircol reagent, lungs were flushed with PBS before excision to clear blood.

Quantification of cytokines. Cytokine levels were assayed by enzyme-linked immunosorbent assays in either BALF, total lung homogenates, or conditioned media from primary AEC culture. ELISAs were performed for the following mouse proteins: IL-10 (DY417, R\&D Systems), Chemerin (DY2325, R\&D Systems), IL-1ra (DY480, R\&D Systems), TGF- $\beta 1$ (both free and total content in the absence or presence of acid activation respectively; DY1679, R\&D Systems), CCL21 (DY457, R\&D Systems), CXCL16 (DY503, R\&D Systems), IL-16 (DY1727, R\&D Systems), CCL2 (DY479, R\&D Systems), CCL12 (DY428, R\&D Systems), and CXCL1 (DY453, R\&D Systems).

Statistics. A Mann Whitney test was used to determine the levels of difference between groups. Values for all measurements are expressed as means $\pm \mathrm{SE}$, and $P$ values for significance are indicated for each experiment.

Study approval. All animal experiments were performed in accordance with national guidelines and were approved by the local ethics committee, Comité d'éthique animale Paris Nord. Human BAL samples were obtained after BAL was performed for a diagnostic purpose and when enough material was available, with standard procedures (47). IPF was diagnosed according to ATS/ERS/JRS/ALAT criteria, including histopathological features of usual interstitial pneumonia (48). The control group included patients without CT-scan evidence of interstitial lung disease (IL-D) who required a bronchoscopy for the diagnosis of lung nodule $(n=3)$, suspicion of hemoptysis $(n=2)$. This study was approved by the local ethics committee (CPP Ile de France 1, no. 0811760).

\section{Author contributions}

VB designed research studies, contributed to the experiments, analyzed the data, and wrote the manuscript. $\mathrm{RD}, \mathrm{TM}, \mathrm{AJ}$, and MJ contributed to the experiments and reviewed the manuscript. MK and PB contributed 
to the adenovirus experiments, and reviewed the manuscript. LAM analyzed the data and reviewed the manuscript. MAS designed research studies, analyzed the data, and reviewed the manuscript. BC designed research studies, analyzed the data, and wrote the manuscript.

\section{Acknowledgments}

This work was supported by MedImmune, la Fondation pour la Recherche Médicale (MT), the LABEX Inflamex (JA), and the "Association pour la fibrose pulmonaire idiopathique Pierre Enjalran." We acknowledge technical contribution from A. Hamimi and S. LyKaSo. We would like to thank Fiona Watt (Centre for Stem Cells and Regenerative Medicine, King's College London, London, United Kingdom) for her gift of the $\mathrm{Ppt}^{-1-}$ transgenic mice and the pathologist Aurélie Cazes (Hôpital Bichat, Paris, France) for her help in the lung fibrosis scoring. We thank Sabine Grootenboer-Mignot for fruitful discussions in the course of this work.

Address correspondence to: Bruno Crestani, Service de Pneumologie A, Hôpital Bichat, 46 rue Henri Huchard, 75018 Paris, France. Phone: 331.40.25.68.00; Email: bruno.crestani@aphp.fr.

1. Garrod D, Chidgey M. Desmosome structure, composition and function. Biochim Biophys Acta. 2008;1778(3):572-587.

2. van den Heuvel AP, et al. Binding of protein kinase B to the plakin family member periplakin. J Cell Sci. 2002;115(Pt 20):3957-3966.

3. Boczonadi V, Määttä A. Annexin A9 is a periplakin interacting partner in membrane-targeted cytoskeletal linker protein complexes. FEBS Lett. 2012;586(19):3090-3096.

4. Beekman JM, Bakema JE, van de Winkel JG, Leusen JH. Direct interaction between FcgammaRI (CD64) and periplakin controls receptor endocytosis and ligand binding capacity. Proc Natl Acad Sci USA. 2004;101(28):10392-10397.

5. Beekman JM, et al. Modulation of FcgammaRI (CD64) ligand binding by blocking peptides of periplakin. J Biol Chem. 2004;279(32):33875-33881.

6. Murdoch $\mathrm{H}$, et al. Periplakin interferes with $\mathrm{G}$ protein activation by the melanin-concentrating hormone receptor-1 by binding to the proximal segment of the receptor C-terminal tail. J Biol Chem. 2005;280(9):8208-8220.

7. Taillé C, et al. Identification of periplakin as a new target for autoreactivity in idiopathic pulmonary fibrosis. Am J Respir Crit Care Med. 2011;183(6):759-766.

8. Cabrera S, et al. Gene expression profiles reveal molecular mechanisms involved in the progression and resolution of bleomycininduced lung fibrosis. Am J Physiol Lung Cell Mol Physiol. 2013;304(9):L593-L601.

9. Fingerlin TE, et al. Genome-wide association study identifies multiple susceptibility loci for pulmonary fibrosis. Nat Genet. 2013;45(6):613-620.

10. Mathai SK, et al. Desmoplakin Variants Are Associated with Idiopathic Pulmonary Fibrosis. Am J Respir Crit Care Med. 2016;193(10):1151-1160.

11. Borradori L, Trüeb RM, Jaunin F, Limat A, Favre B, Saurat JH. Autoantibodies from a patient with paraneoplastic pemphigus bind periplakin, a novel member of the plakin family. J Invest Dermatol. 1998;111(2):338-340.

12. Preisz K, et al. Exacerbation of paraneoplastic pemphigus by cyclophosphamide treatment: detection of novel autoantigens and bronchial autoantibodies. Br J Dermatol. 2004;150(5):1018-1024.

13. Aho S, et al. Periplakin gene targeting reveals a constituent of the cornified cell envelope dispensable for normal mouse development. Mol Cell Biol. 2004;24(14):6410-6418.

14. Warburton D, Shi W, Xu B. TGF- $\beta$-Smad3 signaling in emphysema and pulmonary fibrosis: an epigenetic aberration of normal development? Am J Physiol Lung Cell Mol Physiol. 2013;304(2):L83-L85.

15. Feng XH, Derynck R. Specificity and versatility in tgf-beta signaling through Smads. Annu Rev Cell Dev Biol. 2005;21:659-693.

16. Shi Y, Wang YF, Jayaraman L, Yang H, Massagué J, Pavletich NP. Crystal structure of a Smad MH1 domain bound to DNA: insights on DNA binding in TGF-beta signaling. Cell. 1998;94(5):585-594.

17. Bellaye PS, et al. The small heat-shock protein $\alpha$ B-crystallin is essential for the nuclear localization of Smad4: impact on pulmonary fibrosis. J Pathol. 2014;232(4):458-472.

18. Pedroza M, et al. STAT-3 contributes to pulmonary fibrosis through epithelial injury and fibroblast-myofibroblast differentiation. FASEB J. 2016;30(1):129-140.

19. Tonoike $Y$, et al. Adhesion molecule periplakin is involved in cellular movement and attachment in pharyngeal squamous cancer cells. BMC Cell Biol. 2011;12:41.

20. Morgan AJ, et al. Expression of CXCR6 and its ligand CXCL16 in the lung in health and disease. Clin Exp Allergy. 2005;35(12):1572-1580.

21. Pierce EM, et al. Therapeutic targeting of CC ligand 21 or CC chemokine receptor 7 abrogates pulmonary fibrosis induced by the adoptive transfer of human pulmonary fibroblasts to immunodeficient mice. Am J Pathol. 2007;170(4):1152-1164.

22. Lin Y, et al. Chemerin aggravates DSS-induced colitis by suppressing M2 macrophage polarization. Cell Mol Immunol. 2014;11(4):355-366.

23. Bondue B, et al. ChemR23 dampens lung inflammation and enhances anti-viral immunity in a mouse model of acute viral pneumonia. PLoS Pathog. 2011;7(11):e1002358.

24. Demoor T, et al. The role of ChemR23 in the induction and resolution of cigarette smoke-induced inflammation. J Immunol. 2011;186(9):5457-5467.

25. Luangsay S, et al. Mouse ChemR23 is expressed in dendritic cell subsets and macrophages, and mediates an anti-inflammatory activity of chemerin in a lung disease model. J Immunol. 2009;183(10):6489-6499. 
26. Sevilla LM, et al. Mice deficient in involucrin, envoplakin, and periplakin have a defective epidermal barrier. J Cell Biol. 2007;179(7):1599-1612.

27. Wan $\mathrm{H}$, et al. Kruppel-like factor 5 is required for perinatal lung morphogenesis and function. Development. 2008;135(15):2563-2572.

28. Noda S, et al. Simultaneous downregulation of KLF5 and Fli1 is a key feature underlying systemic sclerosis. Nat Commun. 2014;5:5797.

29. Fang F, et al. The early growth response gene Egr2 (Alias Krox20) is a novel transcriptional target of transforming growth factor- $\beta$ that is up-regulated in systemic sclerosis and mediates profibrotic responses. Am J Pathol. 2011;178(5):2077-2090.

30. Djabali K, de Néchaud B, Landon F, Portier MM. AlphaB-crystallin interacts with intermediate filaments in response to stress. J Cell Sci. 1997;110(Pt 21):2759-2769.

31. Perng MD, Cairns L, van den IJssel P, Prescott A, Hutcheson AM, Quinlan RA. Intermediate filament interactions can be altered by HSP27 and alphaB-crystallin. J Cell Sci. 1999;112(Pt 13):2099-2112.

32. Bellaye PS, et al. Antifibrotic role of $\alpha \mathrm{B}$-crystallin inhibition in pleural and subpleural fibrosis. Am J Respir Cell Mol Biol. 2015;52(2):244-252.

33. Pierce EM, et al. Idiopathic pulmonary fibrosis fibroblasts migrate and proliferate to CC chemokine ligand 21. Eur Respir J. 2007;29(6):1082-1093.

34. Chen G, et al. CXCL16 recruits bone marrow-derived fibroblast precursors in renal fibrosis. J Am Soc Nephrol. 2011;22(10):1876-1886.

35. Xia Y, Entman ML, Wang Y. Critical role of CXCL16 in hypertensive kidney injury and fibrosis. Hypertension. 2013;62(6):1129-1137.

36. Saxena A, Khosraviani S, Noel S, Mohan D, Donner T, Hamad AR. Interleukin-10 paradox: A potent immunoregulatory cytokine that has been difficult to harness for immunotherapy. Cytokine. 2015;74(1):27-34.

37. Arai $\mathrm{T}$, et al. Introduction of the interleukin-10 gene into mice inhibited bleomycin-induced lung injury in vivo. Am J Physiol Lung Cell Mol Physiol. 2000;278(5):L914-L922.

38. Nakagome K, Dohi M, Okunishi K, Tanaka R, Miyazaki J, Yamamoto K. In vivo IL-10 gene delivery attenuates bleomycin induced pulmonary fibrosis by inhibiting the production and activation of TGF-beta in the lung. Thorax. 2006;61(10):886-894.

39. Du XY, Leung LL. Proteolytic regulatory mechanism of chemerin bioactivity. Acta Biochim Biophys Sin (Shanghai). 2009;41(12):973-979.

40. Endo M, et al. Induction of arginase I and II in bleomycin-induced fibrosis of mouse lung. Am J Physiol Lung Cell Mol Physiol. 2003;285(2):L313-L321

41. Long HA, Boczonadi V, McInroy L, Goldberg M, Määttä A. Periplakin-dependent re-organisation of keratin cytoskeleton and loss of collective migration in keratin-8-downregulated epithelial sheets. J Cell Sci. 2006;119(Pt 24):5147-5159.

42. Mariani F, Roncucci L. Chemerin/chemR23 axis in inflammation onset and resolution. Inflamm Res. 2015;64(2):85-95.

43. Pechkovsky DV, et al. STAT3-mediated signaling dysregulates lung fibroblast-myofibroblast activation and differentiation in UIP/IPF. Am J Pathol. 2012;180(4):1398-1412.

44. Rice WR, Conkright JJ, Na CL, Ikegami M, Shannon JM, Weaver TE. Maintenance of the mouse type II cell phenotype in vitro. Am J Physiol Lung Cell Mol Physiol. 2002;283(2):L256-L264.

45. Wikenheiser KA, et al. Production of immortalized distal respiratory epithelial cell lines from surfactant protein $\mathrm{C} /$ simian virus 40 large tumor antigen transgenic mice. Proc Natl Acad Sci USA. 1993;90(23):11029-11033.

46. Lareu RR, Zeugolis DI, Abu-Rub M, Pandit A, Raghunath M. Essential modification of the Sircol Collagen Assay for the accurate quantification of collagen content in complex protein solutions. Acta Biomater. 2010;6(8):3146-3151.

47. Quesnel C, et al. Regulation of hepatocyte growth factor secretion by fibroblasts in patients with acute lung injury. Am JPhysiol Lung Cell Mol Physiol. 2008;294(2):L334-L343.

48. Wells AU. The revised ATS/ERS/JRS/ALAT diagnostic criteria for idiopathic pulmonary fibrosis (IPF)--practical implications. Respir Res. 2013;14 Supp1 1:S2. 